\title{
Supporting Information for \\ Quantifying Domestic Used Electronics Flows using a \\ Combination of Material Flow Methodologies: \\ A US Case Study
}

\author{
T. Reed Miller ${ }^{* 1}$, Huabo Duan ${ }^{1}$, Jeremy Gregory ${ }^{1}$, Ramzy Kahhat ${ }^{2}$, Randolph Kirchain ${ }^{1}$ \\ 1. Materials System Laboratory, Engineering Systems Division, Massachusetts Institute of Technology, \\ Cambridge, Massachusetts, United States.
}

Note: Huabo Duan is currently at the Department of Civil Engineering at Shenzhen University.

2. Department of Engineering, Pontificia Universidad Católica del Perú, 1801 Avenida Universitaria, San Miguel, Lima 32, Peru

In this Supporting Information, some of the methods described in the text are explained in detail. Results are provided in table format as well. The structure parallels that of the text.

\section{Contents}

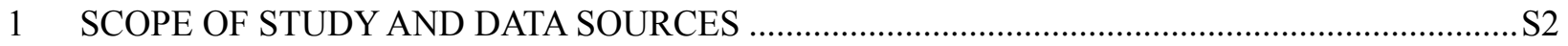

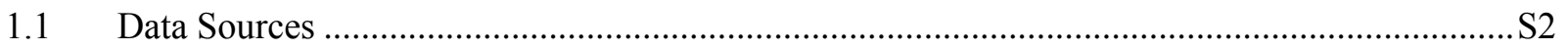

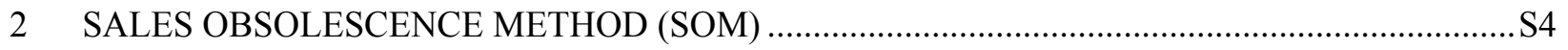

2.1 SOM Residential Generation Estimation Procedure ............................................................. S5

2.2 SOM Residential Collection Estimation Procedure .................................................................... 14

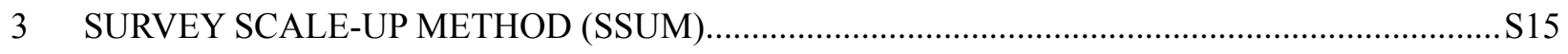

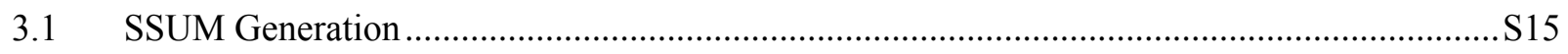

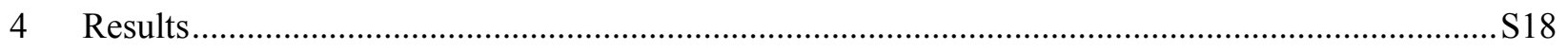

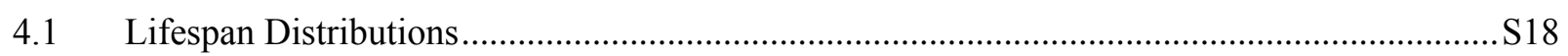

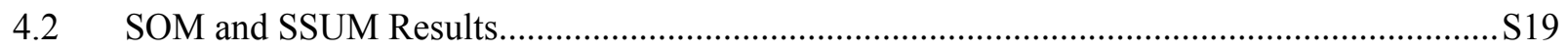

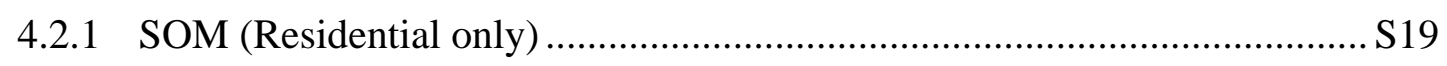

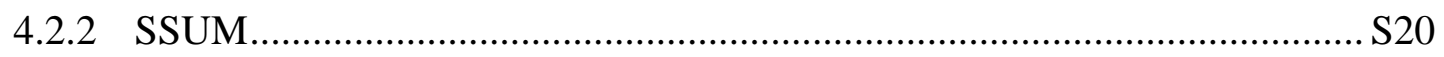

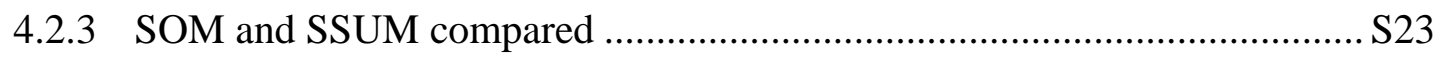

4.2.4 Comparison to Other Sources …....................................................... S27

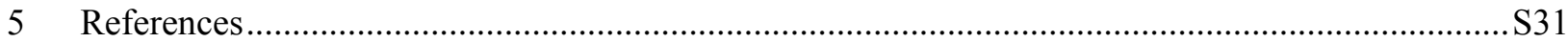




\section{SCOPE OF STUDY AND DATA SOURCES}

\subsection{Data Sources}

\section{Survey Data:}

The survey data used was graciously provided by Dr. Eric Williams and Dr. Ramzy Kahhat. The survey templates can be found in Appendix A: Supplementary Data associated with their article, http://dx.doi.org/10.1016/j.resconrec.2012.07.008

Data used for many steps in both methods are from United States (US) Residential and business/public surveys conducted in 2011 by Kahhat and Williams [1]. These survey data have been applied to both SOM and SSUM methods to estimate the generation and collection. The following excerpt describes the survey methodology employed:

"In this study two online surveys were launched to collect primary data on adoption and end-oflife management of personal computers in the Residential and business/public sector of the United States. The Residential sector study included 1000 completed surveys drawn from a larger panel of 350,000 prospective respondents constructed by the consulting firm Research Now. The sample chosen was representative of 2010 Census data for the adult population for the following parameters: Gender, State, Age, Residential Income, and Educational Attainment. The survey consisted of 15 questions covering three topic areas: demographics, computer ownership and use at home, and computer disposal. Four hundred complete surveys where obtained from the business/public sector. The sample was representative of the United States business/public sector according to geographic location and number of employees within a company. Although it would be desirable to have a sample matching the national distribution of organizations/employees by industry sector (e.g. North American Industry Classification System (NAICS)), the cost of soliciting such a sample was beyond available economic resources. The respondent pool was about 25,000 eligible participants of a panel of IT experts collected by the consulting firm Opinionology. The panel included IT decision makers and asset managers. The survey questionnaire included 15 questions. Both surveys were launched in April 2011 and the questions addressed the 2010 calendar year. All completed surveys were examined by the survey company and research team before included in the analysis. The Residential and business/public sector surveys had a margin of error of $3 \%$ and $5 \%$, respectively, considering a confidence level of $95 \%$. Confidence level and margin of error are based on sample size and sample distribution. Survey questionnaire and results are included in supporting information."

Note that the business/public respondents do not capture a representative sample of the downstream used electronics industries; estimates about the generated used electronics managed by these "intermediary" companies are made with inferences described in Section 3 of this SI.

\section{Sales Data:}

In the study, the sales data utilized was broken down by residential and business/public channels. Due to the proprietary nature of the data it is not presented. Instead, published sales data from US EPA (2011) is visualized for reference in Figure S1. 


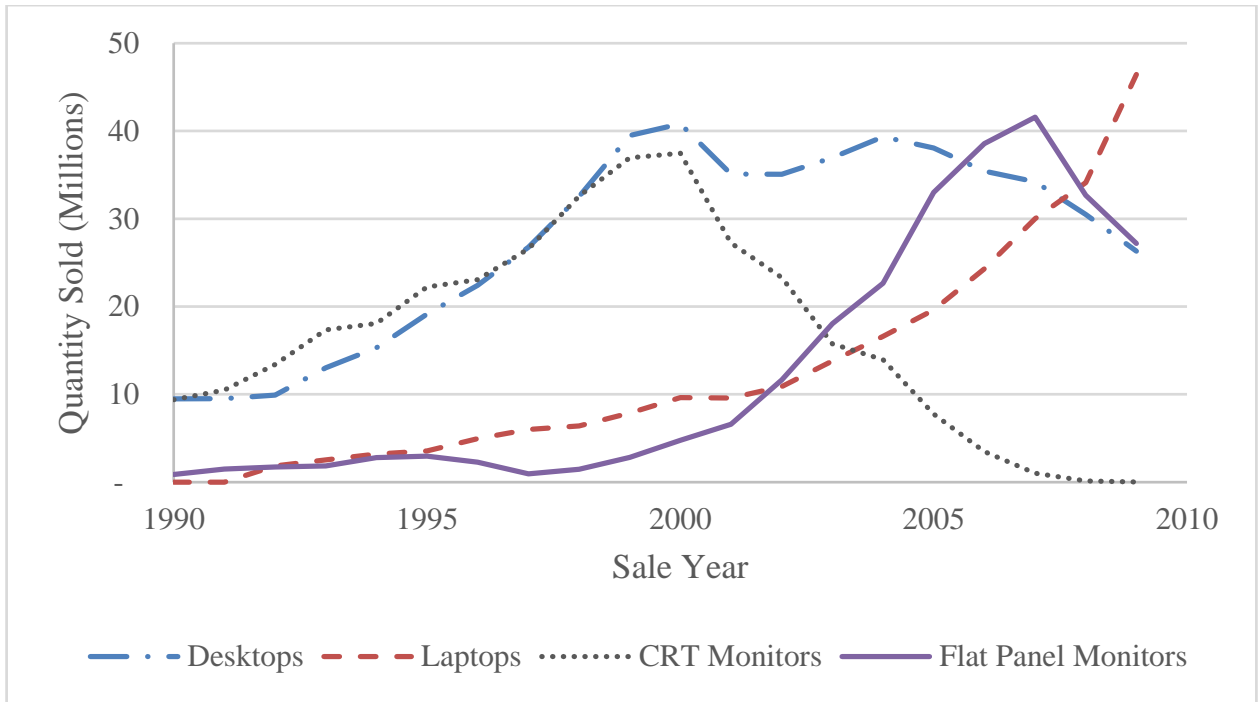
(2011)[2].

Figure S1: Total sales of new computers and monitors in the US, 1990-2010. Data from US EPA

\section{Unit Weight Data:}

The unit weight data for computers (laptop and desktop) and monitors are estimated based on the sampling data in 2010 of used electronics by the Oregon and Washington States[3], with the sample sizes ranging from 1,000 to 10,000 for brands of each type of electronic. The unit weight distributions were modeled from this empirical data.

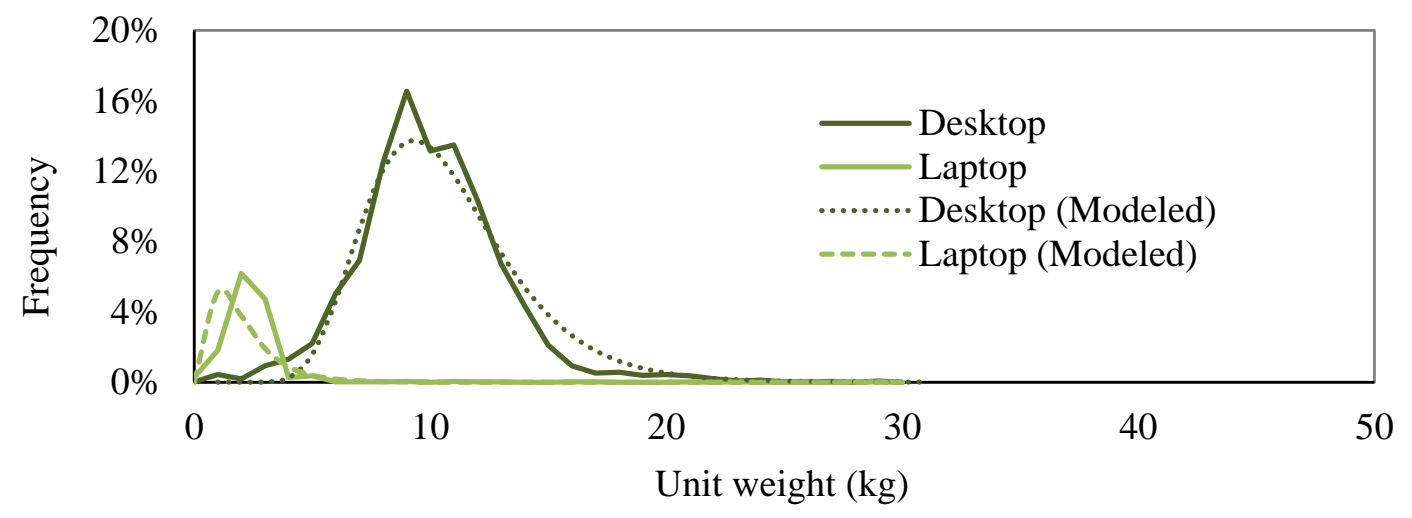

Figure S2: Unit Weight for Computers for Model Parameters 


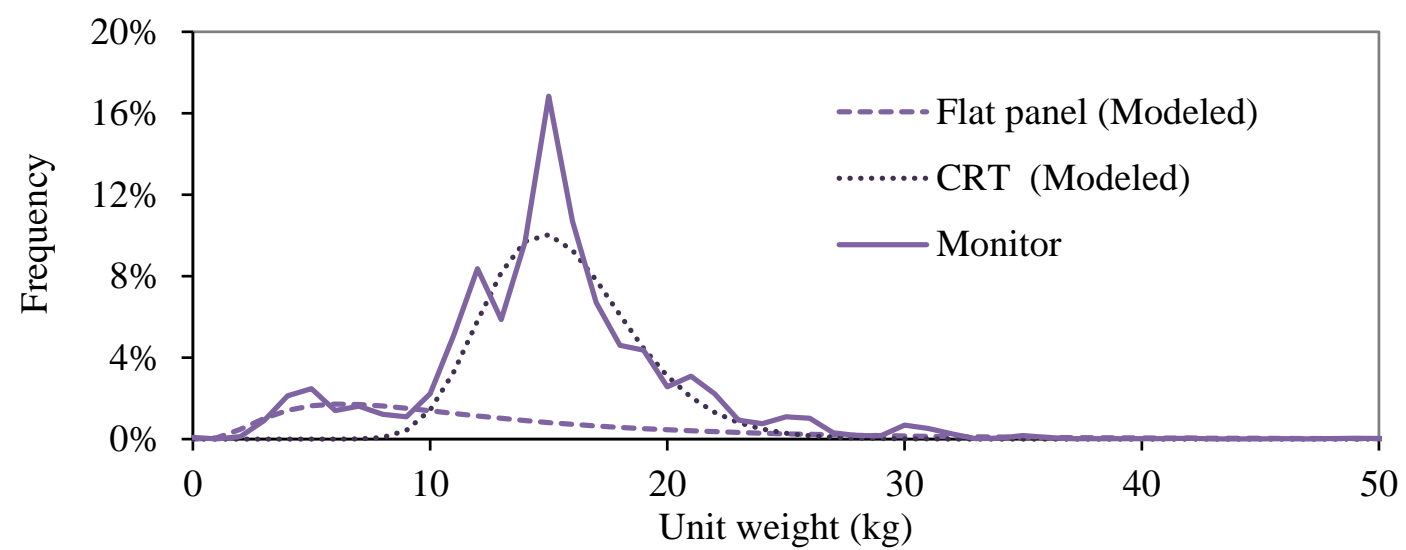

Figure S3: Unit Weight for Monitors for Model Parameters

Table S1: Modeled unit weight distributions of computers and monitors ( $\mathrm{kg}$ )

\begin{tabular}{|l|l|l|l|}
\hline Used Electronics & Distribution & Mean & \multicolumn{1}{|c|}{ Standard Deviation } \\
\hline Desktop & Lognormal & 10.6 & 3.3 \\
\hline Laptop & Lognormal & 3.1 & 1.5 \\
\hline CRT monitor & Lognormal & 15.4 & 1.2 \\
\hline Flat Panel monitor & Lognormal & 10.4 & 2.0 \\
\hline
\end{tabular}

\section{SALES OBSOLESCENCE METHOD (SOM)}

Table S2: Summary Comparison between Methods Employed

\begin{tabular}{cll}
\hline Flow & \multicolumn{1}{c}{ SOM } & \multicolumn{1}{c}{ SSUM } \\
\hline Generation & $\begin{array}{l}\text { Combines product sales data with models } \\
\text { of product lifespans based on survey data }\end{array}$ & $\begin{array}{l}\text { Amplification of survey respondents' } \\
\text { generation habits in a given year based on } \\
\text { sales data and purchase habits }\end{array}$ \\
\hline \multirow{2}{*}{ Collection } & $\begin{array}{l}\text { Combines generation results with models } \\
\text { of collection rates from survey data }\end{array}$ & $\begin{array}{l}\text { Amplification of survey respondents } \\
\text { collection habits in a given year based on } \\
\text { sales data and purchase habits }\end{array}$ \\
\hline \multirow{2}{*}{ Limitations } & $\begin{array}{l}\text { Inherent errors in sales and survey data } \\
\text { including difficulty recalling older devices. } \\
\text { Lifespans are approximations }\end{array}$ & $\begin{array}{l}\text { Inherent errors in sales and survey data } \\
\text { including difficulty recalling older devices. } \\
\text { Assumptions about fate after generation. }\end{array}$ \\
\hline
\end{tabular}




\subsection{SOM Residential Generation Estimation Procedure}

\section{Determine the residential sales of a product in a region over a time period.}

(Note: This is described in the manuscript.)

II. Determine the typical distribution of residential lifespans, including use and storage, for the product over a time period. Also determine the typical distribution of time until an electronic product is reused, and the proportion of products that are expected to be reused.

(Note: Additional details here to support the information in the manuscript.)

Figure S4 shows an overview of the pathways, flows, and possession spans considered in the generation model. The following sections describe the survival analysis techniques employed to derive and estimate Weibull distributions of possession span, no informal reuse $\lambda$. They also describe the approach for estimating lognormal distributions of possession span, pre-informal reuse $\delta$.

\begin{tabular}{|c|c|c|c|c|c|}
\hline Pathway & Quantity method & \multicolumn{4}{|c|}{ Flows of electronics through generation } \\
\hline \multirow{4}{*}{$\begin{array}{l}\text { One Use } \\
\text { before } \\
\text { Generation } \\
\text { (O) }\end{array}$} & \multirow{4}{*}{$\begin{array}{l}\text { Quantity based } \\
\text { on new sales less } \\
\text { forecast of } \\
\text { informal reuse in } \\
\text { future years }\end{array}$} & \multicolumn{4}{|c|}{ Generation } \\
\hline & & \multirow{3}{*}{$\begin{array}{l}\text { First Owner } \\
\text { Possession span, } \\
\text { no informal reuse }\end{array}$} & \multirow{2}{*}{\multicolumn{3}{|c|}{$\begin{array}{l}\text { Collection \& } \\
\text { Recycling }\end{array}$}} \\
\hline & & & & & \\
\hline & & & \multicolumn{3}{|c|}{$\stackrel{\text { Landfill }}{\longrightarrow}$} \\
\hline \multirow{4}{*}{$\begin{array}{l}\text { Formal } \\
\text { Reuse after } \\
\text { Generation } \\
\text { \& Collection } \\
\text { (C) }\end{array}$} & \multirow{4}{*}{$\begin{array}{l}\text { Quantity based } \\
\text { on estimate of } \\
\text { reuse in reuse } \\
\text { year \& fraction } \\
\text { that is formal }\end{array}$} & \multirow{4}{*}{$\delta \bigwedge$} & \multirow{4}{*}{$\begin{array}{l}\text { Collection } \\
\& \text { Formal } \\
\text { Reuse }\end{array}$} & \multicolumn{2}{|c|}{ Generation } \\
\hline & & & & \multirow{3}{*}{$\begin{array}{l}\text { Second Owner } \\
\text { Possession span, } \\
\text { no informal reuse }\end{array}$} & Collection \& \\
\hline & & & & & $\stackrel{\text { Recycling }}{\longrightarrow}$ \\
\hline & & & & & Landfill \\
\hline \multirow{4}{*}{$\begin{array}{l}\text { Informal } \\
\text { Reuse } \\
\text { before } \\
\text { generation } \\
\text { (I) }\end{array}$} & \multirow{4}{*}{$\begin{array}{l}\text { Quantity based } \\
\text { on estimate of } \\
\text { reuse in reuse } \\
\text { year \& fraction } \\
\text { that is informal }\end{array}$} & \multirow{4}{*}{$\frac{\delta \bigwedge}{\frac{\delta \text { First Owner }}{\text { Possession span, }}}$} & \multirow{4}{*}{$\begin{array}{l}\text { Informal } \\
\text { Reuse }\end{array}$} & \multicolumn{2}{|c|}{ Generation } \\
\hline & & & & & Collection \& \\
\hline & & & & Second Owner & Recycling \\
\hline & & & & $\begin{array}{l}\text { Possession span, } \\
\text { no informal reuse }\end{array}$ & Landfill \\
\hline
\end{tabular}

Figure S4: (This is a repeat of Figure 1 in the manuscript for convenience.) Flows of electronic products undergoing one use before generation $(O)$, formal reuse after generation and collection $(C)$, and informal reuse before generation (I). Above each owner is an illustration of the distribution of the possession span, no informal reuse $\lambda$ or possession span, pre-informal reuse $\delta$. The dotted line indicates that the product is generated at that point. Note that products in path $C$ are generated twice.

\section{i. Prepare the Residential survey data.}

The survey data received from the survey firm needed to be consolidated, because the data originally was arranged by respondent instead of by electronic. There were two sets of relevant questions, requiring separate preparation: questions pertaining to those had undergone End of Use (EOU) activity, and electronics that were still in the home ("censored"). Some of the items 
undergoing EOU activity were considered to be "failures" and others "censored" in Table S3.

Table S3: Designation of Failure, Generation, and Collection by End of Use Activity

\begin{tabular}{|l|l|l|l|}
\hline End of Use Activity & Fail? & Category & Generated? \\
\hline Storage off-site & Censor & Not Included & Not Generated \\
\hline Donated to friend/family within Residential & Fail & Informal Reuse & Not Generated \\
\hline NA Did not discard & Censor & Not Included & Not Generated \\
\hline Disposal via curbside garbage collection & Fail & Trash & Generated \\
\hline Recycled via curbside recycling program & Fail & Collected & Generated \\
\hline Returned to collection depot for recycling & Fail & Collected & Generated \\
\hline Returned to retailer & Fail & Collected & Generated \\
\hline $\begin{array}{l}\text { Returned to municipality during a special collection } \\
\text { event }\end{array}$ & Fail & Collected & Generated \\
\hline Returned to manufacturer & Fail & Collected & Generated \\
\hline Donated to friend/family outside of Residential & Fail & Informal Reuse & Not Generated \\
\hline Donated to a charitable organization & Fail & Informal Reuse & Not Generated \\
\hline $\begin{array}{l}\text { Other donation } \\
\text { Returned to seller after lease expired }\end{array}$ & Fail & Informal Reuse & Not Generated \\
\hline Sold online (e.g. eBay) & Fail & Collected & Generated \\
\hline Sold locally & Fail & Informal Reuse & Not Generated \\
\hline Sold to an acquaintance/friend/family & Fail & Informal Reuse & Not Generated \\
\hline Other & Fail & Informal Reuse & Not Generated \\
\hline & Censor & Not Included & Not Generated \\
\hline
\end{tabular}

\section{ii. Determine the age of products either at the point of "failure", or at the time of "censor" (a product is censored if it is still with the owner when surveyed). Where possible, screen the responses by the respondent's precision of estimating the year purchased in comparison estimating time in use and storage (cutoff of 1 year was deemed reasonable).}

Equation S1 below illustrates how the precision metric was calculated. Note that this metric cannot be calculated for those electronics that reached EOU, because the survey asked solely about lifespan in the home, and not about year of purchase. The only quality control metric available for electronics at EOU was to ensure that when respondents reported about the lifespan of EOU electronics and separately about the EOU activity, that the type of electronic matched across the two questions (eg. laptop and laptop, not laptop and desktop). Mismatches were excluded.

$$
\begin{aligned}
& \text { Equation S1: Determination of Precision of Respondent's "Censored” Electronics } \\
& \text { Precision = Year of Survey - Year Purchased - Use - Storage }
\end{aligned}
$$

In Figure S5, it can be seen that the vast majority of US respondents correctly reported both the year purchased and the corresponding time in use and time in storage of laptops quite precisely. A one year was chosen for all products because it is reasonable. 


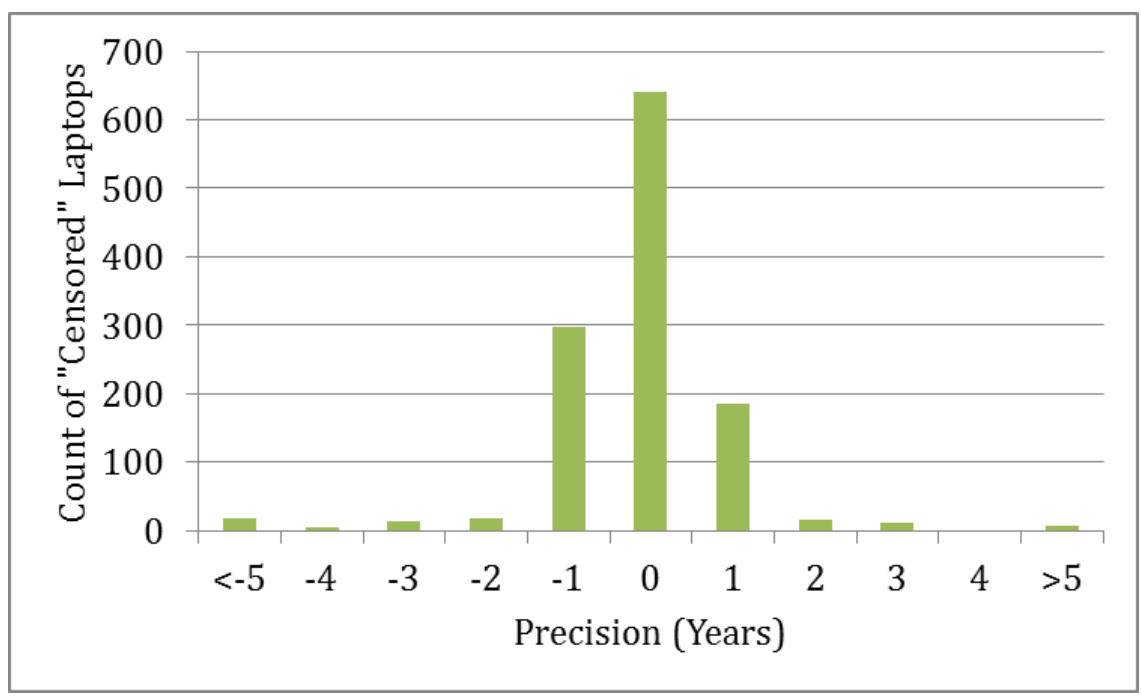

Figure S5: Respondents' Precision of Estimating US Laptop Age and Time at Home

\section{iii. Determine the year that the product was purchased.}

For "censored" electronics still in the home, the year purchased was given directly by the respondents. For electronics that reached EOU, Equation S2 below was used.

Equation S2: Determination of Year of Purchase of Electronics at EOU

Year Purchased $=$ Year at EOU -Use - Storage

\section{iv. Use Stata ${ }^{\circledR} 12.1$ to produce Kaplan-Meier (K-M) survivor curves and subsequently \\ Weibull regressions for all of the products together. Use these K-M curve and associated Weibull regression to each year of purchase.}

The following code was input into Stata ${ }^{\circledR}$ 12.1, and relevant output and comments are included.

- Set data for survival analysis: stset age, failure(failure)

- Describe data to ensure it was processed correctly: stdescribe

- K-M Survival Analysis: sts list

This data, which lists the K-M curve data for the modeled survival curve and the $95 \%$ confidence interval is copied into Microsoft Excel ${ }^{\circledR}$ for the next step.

sts graph 


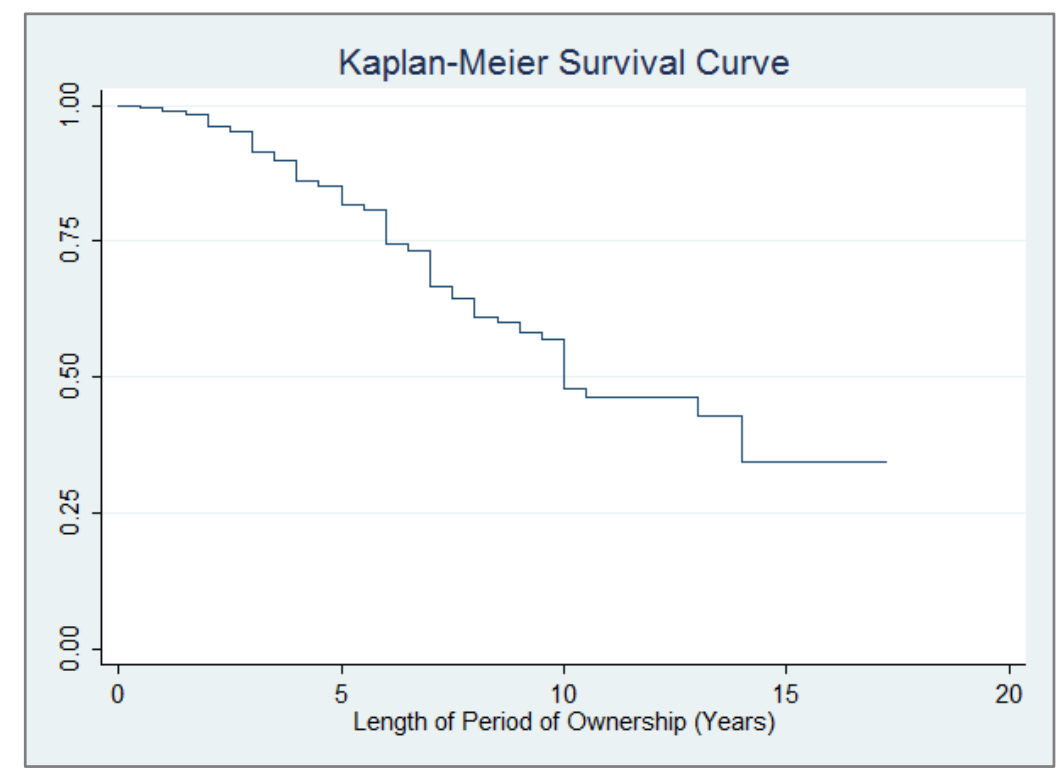

Figure S6: Kaplan-Meier Survival Curve for US Residential Laptops

- Weibull Regression:

streg year, dist(weibull)

This returns the information about the Weibull regression for the laptop dataset. Note that $p$ is the scale factor used to model Weibull distributions.

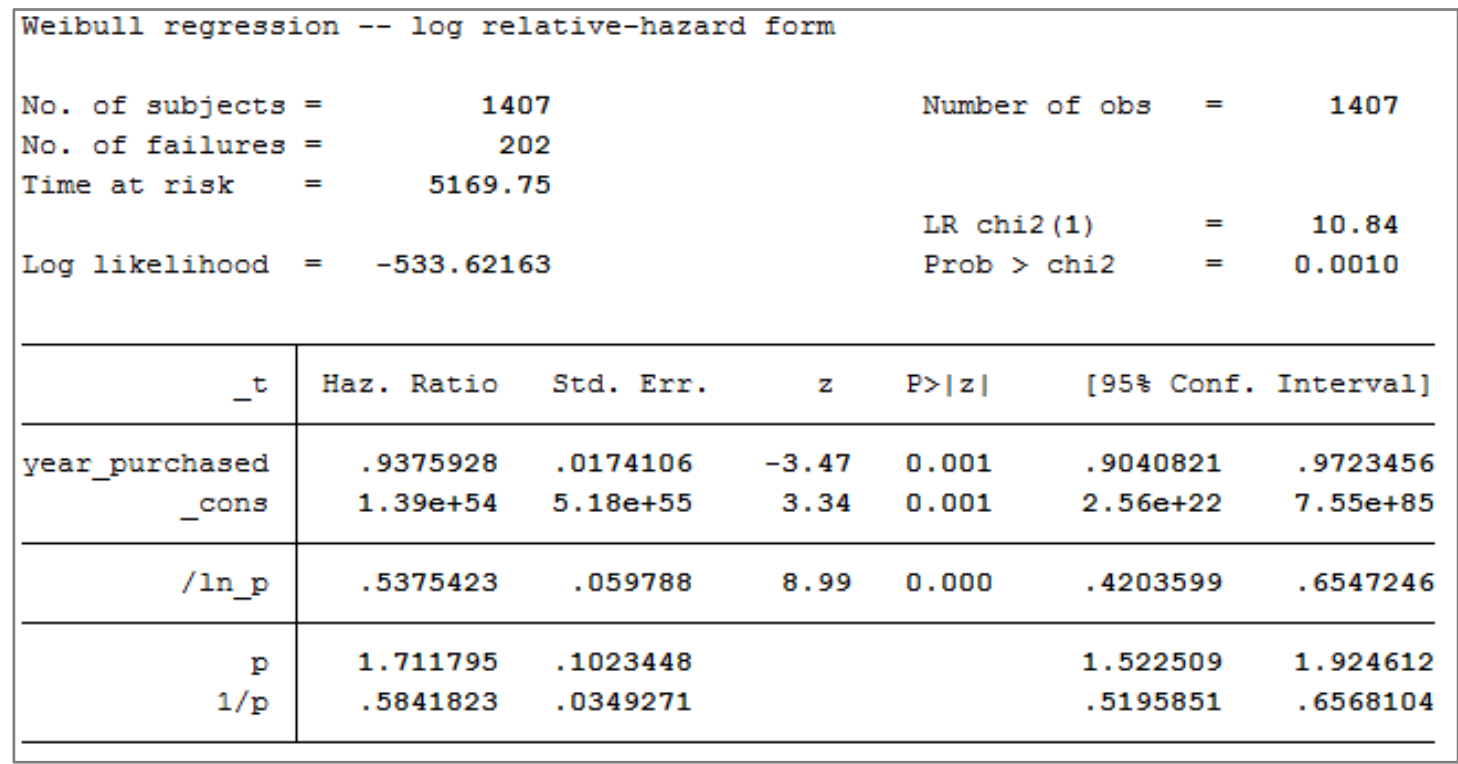

Figure S7: Stata ®Weibull Regression Analysis for US Residential Laptops

This graphs the survival curve based on the Weibull regression; Figure S6 models the K-M survival curve in Figure S8 with the parameters in Figure S7.

stcurve, surviv 


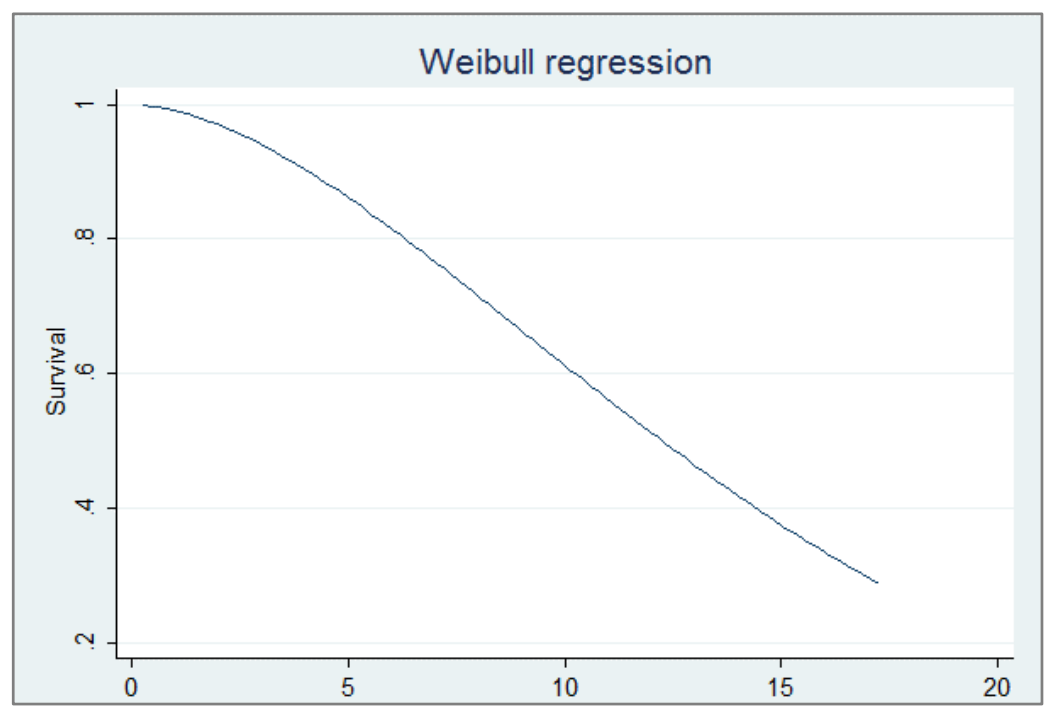

Figure S8: Graph of Weibull Regression Model for possession span, no informal reuse $\lambda$ of residential laptops.

\section{v. Fit additional parameters for the Weibull regression to the K-M curves.}

In order to define a Weibull distribution, both the scale and shape parameter are needed. It is perhaps possible but difficult to extract the shape parameters from the Weibull regression data, and therefore the data from sts list is copied into Microsoft Excel ${ }^{\circledR}$ and the Solver add-in is used to find the shape parameters minimizing the squared error between an inverse cumulative Weibull model and the K-M survivor curves (Figure S9).

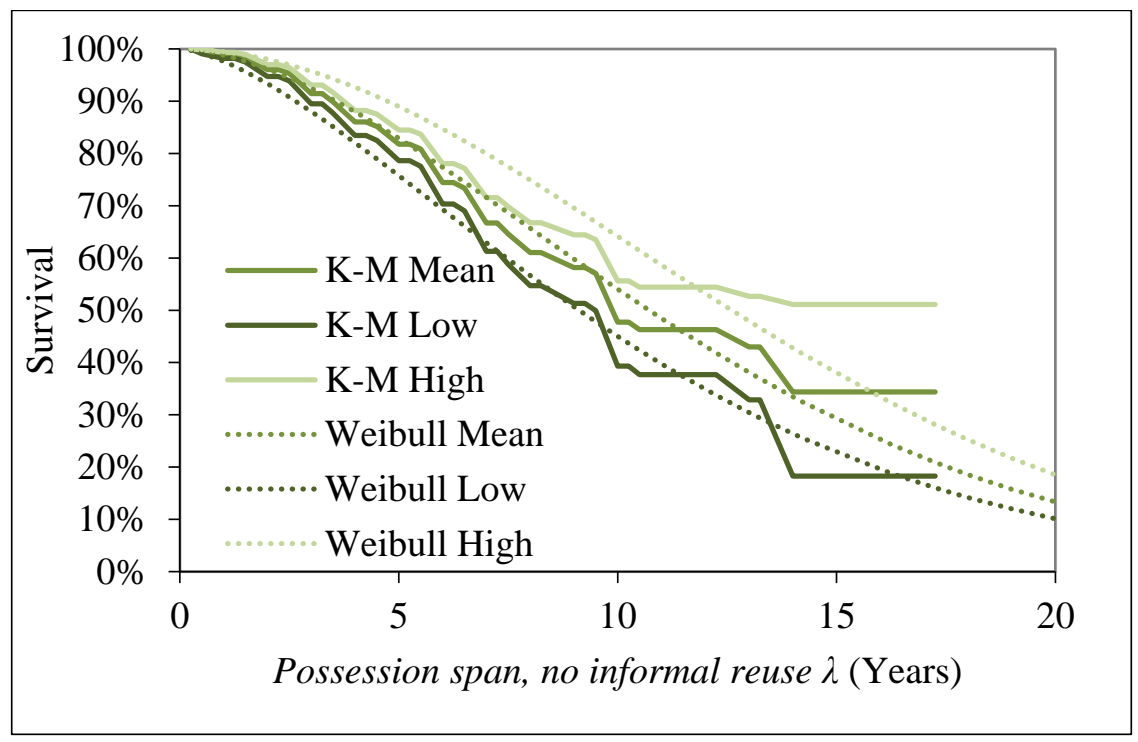

Figure S9: Comparison between K-M Curves and OLS Fit Weibull Regression Curves for Mean, and Low and High Bounds of 95\% Confidence Interval for US Residential Laptops.

vi. Transform the results of the Weibull regression into a probability density function, which will be used as the distribution of possession span, no informal reuse $\lambda$. 
Using the parameters found through the Weibull regression (scale parameters) and fit with minimum squared error (shape parameters), the distributions sought for the possession span, no informal reuse $\lambda$ are modeled with the Microsoft ${ }^{\circledR}$ Excel Weibull. Dist function. Note that the typical length is considerably longer than that modeled in the Literature method, shown in Figure S10. This is likely owing to an underestimation of storage time in the literature, or issues applying the survival analysis method to products which are relatively new to the market since many of the products are still in homes and thus censored and relatively few have been generated.

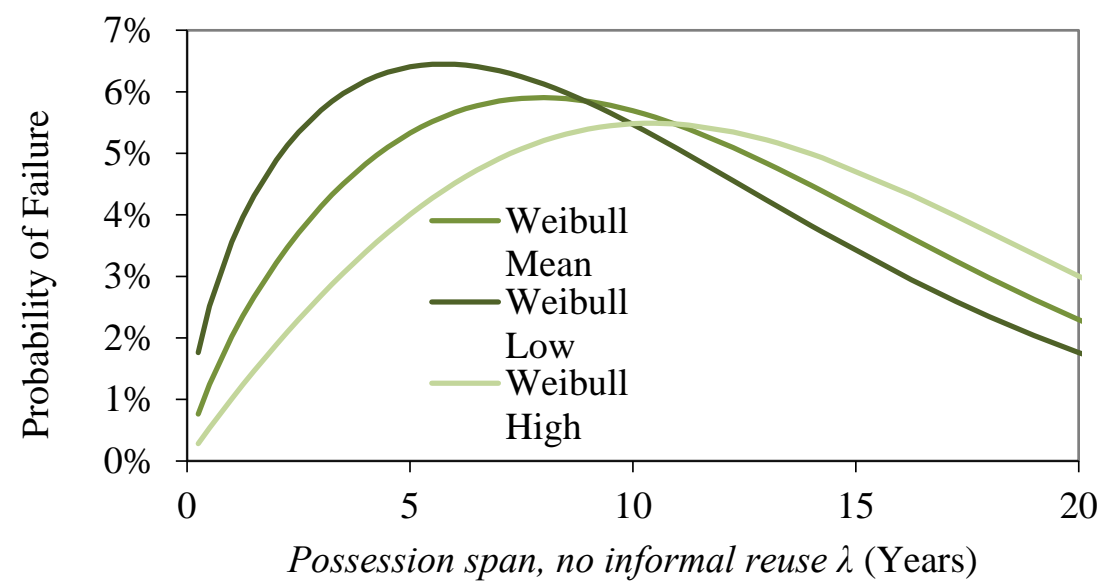

Figure S10: Distribution of US residential laptops possession span, no informal reuse $\lambda$

Below Figure S11 in is a histogram of the distribution of length of time until an electronic is reused (possession span, pre-informal reuse) $\delta$. The mean was allowed to vary $+/-2$ years, and the standard deviation was allowed to vary $+/-10 \%$ in the Monte Carlo simulation. The survey data are the 100 laptops which went toward Informal Reuse at EOU (see Table S3). This is input in the generation prediction model.

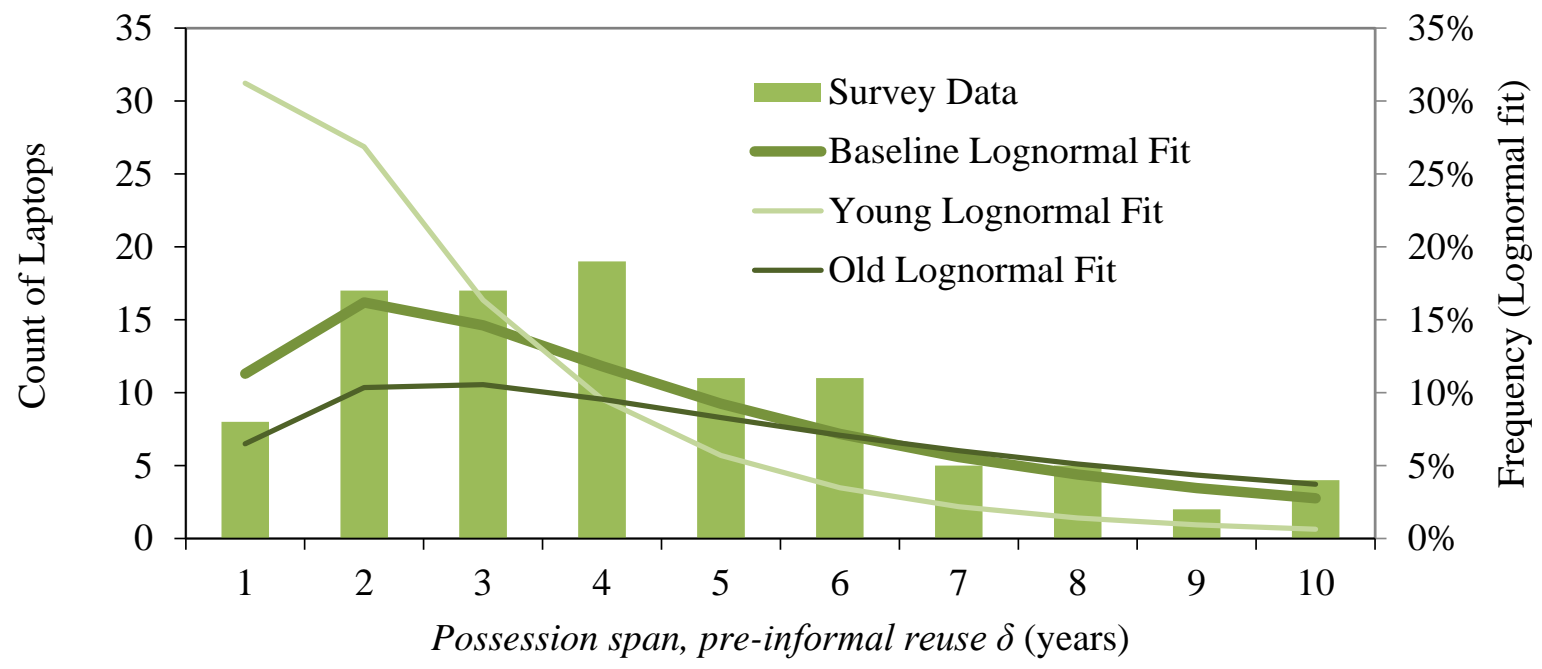

Figure S11: Histogram and Fitted Lognormal Distributions of residential laptop possession span, pre-informal reuse $\delta$ 
vii. During the Monte Carlo simulation, allow the parameters of the regression to vary between a 95\% confidence interval and allow the entire distribution to shift left and right one year to account for allowable error in the respondents' precision. Figure S12 displays some of the $\mathbf{1 0 , 0 0 0}$ distributions modeled during the Monte Carlo simulation.

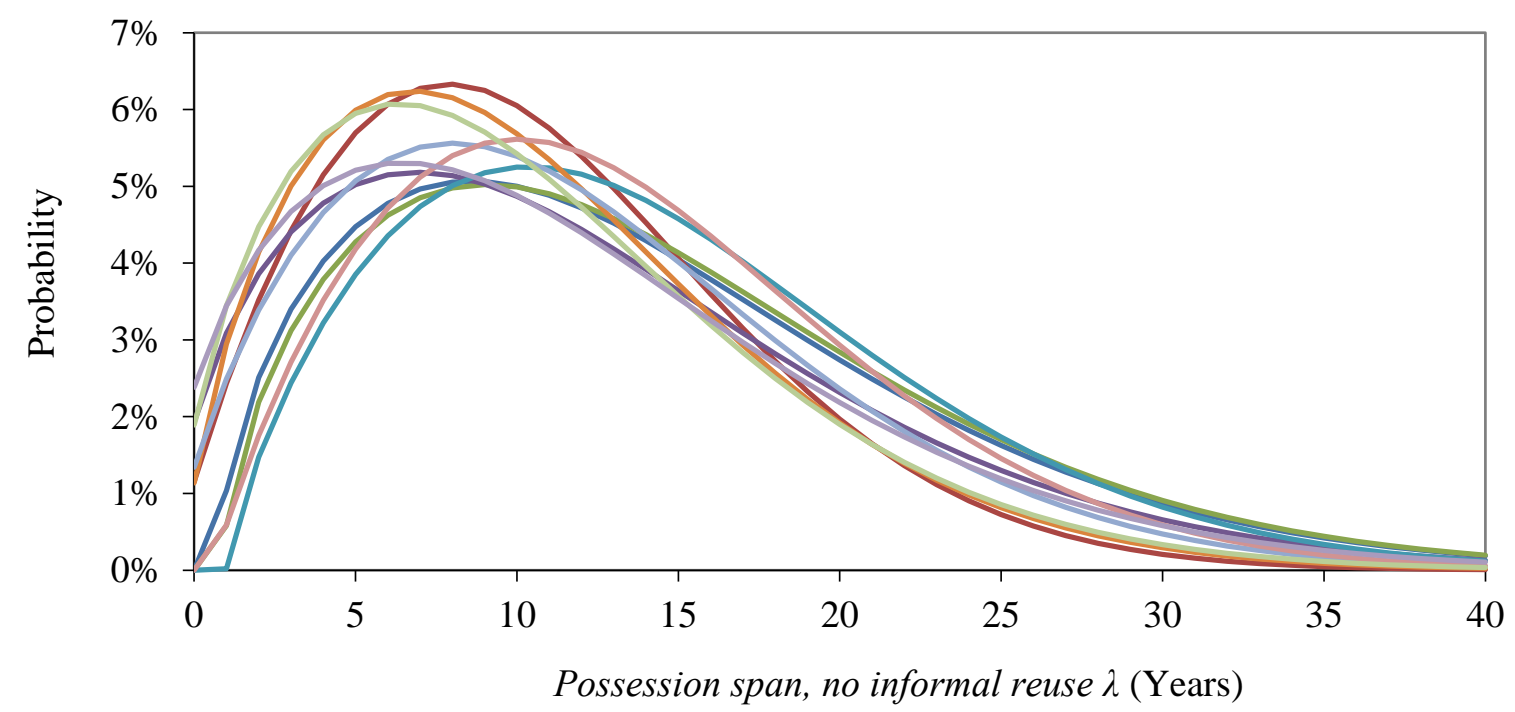

Figure S12: Random sample of distributions of US residential laptop possession span, no informal reuse $\lambda$

III. Calculate how many residential products are predicted to be generated in a given year using the sales and lifespan information.

(Note: Additional details here to support the information in the manuscript.)

The following series of equations were used to model the quantity of electronics that are only used once before generation $(O)$, those that are informally reused before generation $(I)$, and those that are formally reused after a first round of generation and collection $(C)$.

In order to determine in which year $y$ each group $(O, I$, and $C)$ is likely to be generated, it is assumed that reuse purchases ( $I$ and $C$ ) in a given year $s$ are strongly correlated with new sales in the same year $s$. It makes sense that popularity of used products trends with the popularity of new products. The ratios $\beta$ of used to new purchases in the survey data from 2000 to 2010 were modeled in order to capture this phenomenon, as shown in Equation $\mathrm{S} 3 ; \beta$ was approximately 0.1 for the products in the study. See Figure $\mathrm{S} 13$ for a time series of $\beta$ across the four products.

Equation S3: Ratio $\beta$ of used to new purchases

$$
\beta=\frac{\text { Sales }_{\text {Used }}(s)}{\text { Sales }_{\text {New }}(s)}
$$




\section{Beta: Used/New}

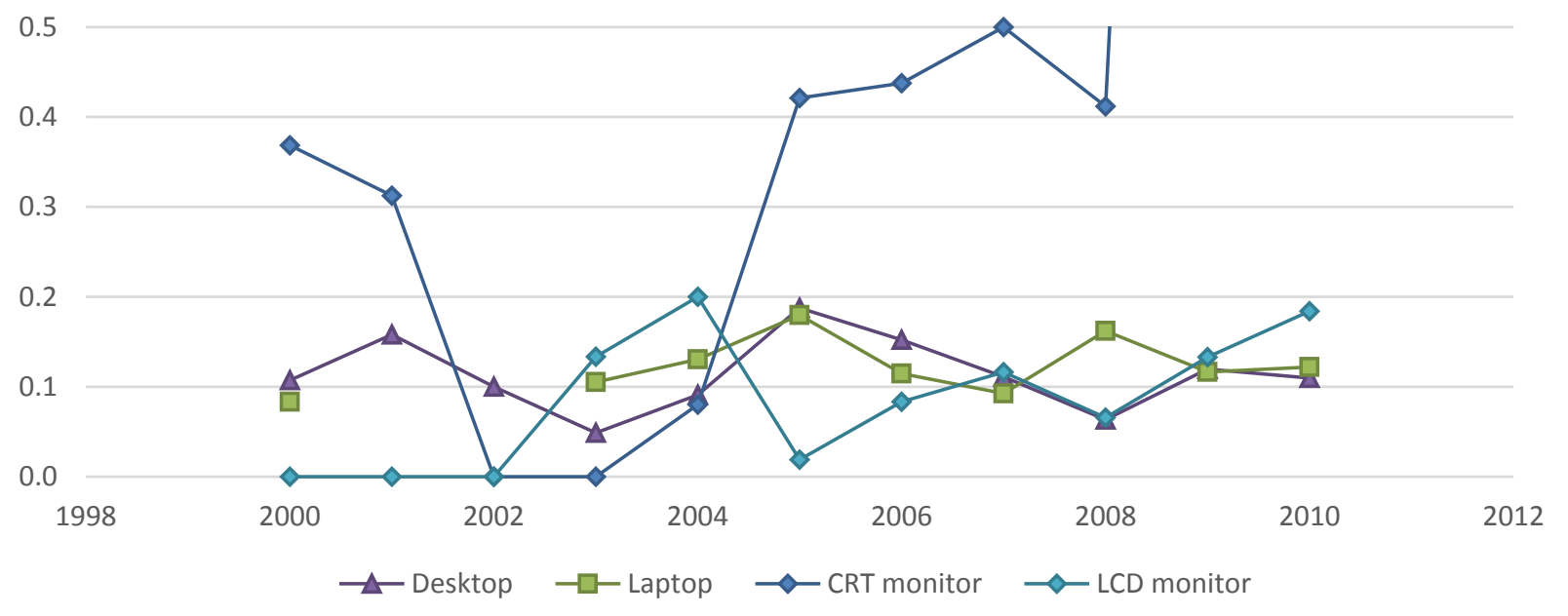

Figure S13: Calculation of $\beta$ for computers and monitors. $\beta$ calculated for CRT monitors varies widely over time, likely due to the small volume of sales (with effectively no sales in 2009) and therefore a relatively small number of relevant survey responses. The other products fluctuate around $\beta=0.1 . L C D$ monitors were not sold until 2001, so $\beta$ is N/A in years 2000-2002.

The next step was to approximate the fraction $\alpha$ of used purchases that occurred through informal reuse $(I)$ as compared to formal reuse after generation and subsequent collection $(C)$. The survey questions asked if electronics still in the home were purchased used or new, and separately asked if electronics that reached EOU were managed in ways that were classified as informal reuse and collection. The difficulty in estimating $\alpha$ is that it is unclear what the probability of domestic formal reuse after collection is. Since far more electronics that reached EOU went to informal reuse than collection, a wide range of 0.2 to 1 was assigned to $\alpha$ and allowed to vary in the Monte Carlo simulation.

Equation S4: Fraction a of used purchases that occurred through informal reuse (I) as compared to any reuse after generation and subsequent collection $(C)$

$$
\alpha=\frac{\operatorname{Sales}_{I}(s)}{\operatorname{Sales}_{I}(s)+\operatorname{Sales}_{C}(s)}
$$

Combining estimates of $\beta$ and $\alpha$ with new sales quantities, we can estimate the sale quantities of used products undergoing informal or formal reuse which occurs $\delta$ years after being sold new, as shown in equations Equation S5 and Equation S6, respectively.

Equation S5: Sales of used products that are undergoing informal reuse I

$$
\operatorname{Sales}_{I}(s+\delta)=\operatorname{Sales}_{N e w}(s) \times \beta \times \alpha
$$

Equation S6: Sales of used products that are undergoing formal reuse C

$$
\operatorname{Sales}_{C}(s+\delta)=\operatorname{Sales}_{N e w}(s) \times \beta \times(1-\alpha)
$$

Equation S7 shows that all of the new purchases in a given year were assumed to undergo one use 
before generation $(O)$, less those which are originally bought in year $s$ and predicted to be informally reused before generation $(I)$ in future years $s+\delta$, starting one year after the current sales year. Doing so avoids double-counting the generation of the same product. Since the sales of used electronics is modeled in relation to the sales of new electronics, the quantity of electronics informally reused in future years needs to be estimated. However, that estimation requires the forecast of sales data. This is accomplished either by incorporating market analyst projections, or by using an annual sales growth rate and allowing it to vary between the range of growth rates from prior years. In some cases where early historic sales data (1990-1994) were not available, a backcast annual sales growth rate was used, and allowed to vary between the range of growth rates in subsequent years.

Equation S7: Sales of electronics that undergo one use before generation $(O)$

$$
\operatorname{Sales}_{O}(s)=\operatorname{Sales}(s)-\sum_{s+1} P(\delta, s+\delta) * \operatorname{Sales}_{I}(s+\delta)
$$

In cases where the product initially experienced exponential growth in sales (particularly laptops), the model for purchases that undergo one use before generation $(O)$ is insufficient. In the early years of product sales, the quantity of single use purchases $(O)$ was often found to be negative. This occurs because the demand for reused items in future years was larger than could be supplied by the small sales in early years. To account for this in a robust manner, the model could allow for an increasing $\alpha$ over time, or make a more complex model where the mean of $\delta$ grows older over time. Here, an approximation was used. The purchases that undergo one use before generation $(O)$ of the first few years of exponential growth of a product were based on the mean proportion of total residential sales to those purchases in subsequent years (roughly 10 years), shown in Equation S8; this parameter varied uniformly around the mean (which was 0.5 for laptops) in Monte Carlo simulations. An interpretation of this approximate method could be that the reused items purchased in subsequent years were also purchased from the business/public sector to meet demand, which is not explicitly captured here.

Equation S8: Approximate sales of electronics that undergo one use before generation $(O)$ for initial years in exponential growth in sales

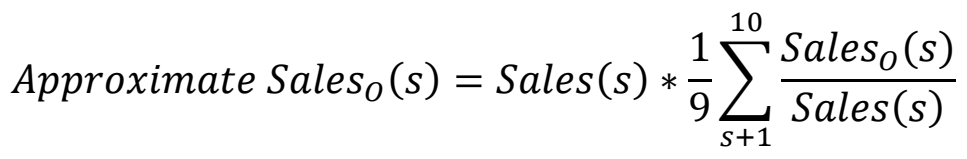

Expanding on Equation S8, the total generation in year $y$ is the sum of applications of to the three groups, as shown below in Equation S9 (Equation 1 in the text).

Equation S9: Detailed Expression of Total Generation of Used Electronics in Year y

$$
\begin{aligned}
& \text { Generated }(y)= \\
& \sum_{s}^{y} \operatorname{Sales}_{O}(s) * \lambda(y-s)+\operatorname{Sales}_{I}(s) * \lambda(y-(s+\delta))+\operatorname{Sales}_{C}(s) * \lambda(y-(s+\delta))
\end{aligned}
$$




\subsection{SOM Residential Collection Estimation Procedure}

Calculate how many of the residential generated products are predicted to be collected in a given year by applying collection rates.

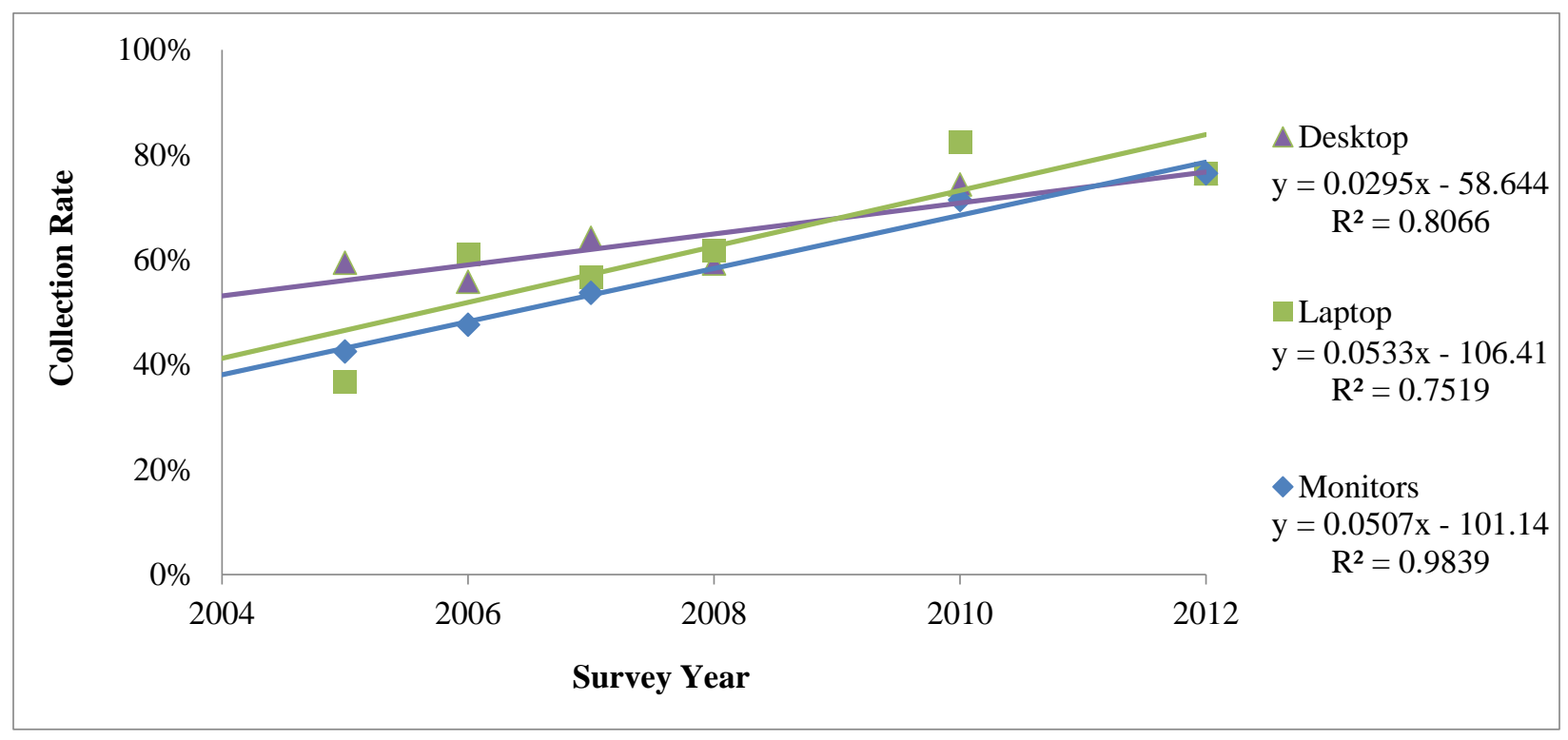

Figure S14: US residential used electronics collection rates. Data points calculated from five surveys [1, 4-7], linear regressions fit the data well (note $R 2$ values). 


\section{SURVEY SCALE-UP METHOD (SSUM)}

Figure S15 presents the end-of-use path specified by the survey respondent with the assigned endof-use path for each scenario. Note that storage, donation to a friend/family within household, and did not discard were not considered to be generation pathways and excluded.

\begin{tabular}{|c|c|c|c|c|c|c|c|c|c|c|c|c|}
\hline & \multicolumn{4}{|c|}{ Intended End-of-Use Scenario } & \multicolumn{4}{|c|}{ Lower Reuse Scenario } & \multicolumn{4}{|c|}{ Higher Export Scenario } \\
\hline & Reuse & Recycle & Landfill & Export & Reuse & Recycle & Landfill & Export & Reuse & Recycle & Landfill & Export \\
\hline \multicolumn{13}{|l|}{ Storage } \\
\hline \multicolumn{13}{|l|}{ Donated to friend/family within household } \\
\hline \multicolumn{13}{|l|}{ Did not discard } \\
\hline Disposal via curbside garbage collection & & & $100 \%$ & & & $20 \%$ & $80 \%$ & & & & $100 \%$ & \\
\hline Recycled via curbside recycling program & $10 \%$ & $90 \%$ & & & & $100 \%$ & & & & $70 \%$ & & $30 \%$ \\
\hline Returned to collection depot for recycling & $10 \%$ & $90 \%$ & & & & $100 \%$ & & & & $70 \%$ & & $30 \%$ \\
\hline Returned to retailer & $10 \%$ & $90 \%$ & & & & $100 \%$ & & & & $70 \%$ & & $30 \%$ \\
\hline Returned to municipality during a collection event & $10 \%$ & $90 \%$ & & & & $100 \%$ & & & & $70 \%$ & & $30 \%$ \\
\hline Returned to manufacturer & $10 \%$ & $90 \%$ & & & & $100 \%$ & & & & $70 \%$ & & $30 \%$ \\
\hline Donated to friend/family outside of household & $90 \%$ & $10 \%$ & & & $80 \%$ & $20 \%$ & & & $80 \%$ & & & $20 \%$ \\
\hline Donated to a charitable organization & $90 \%$ & $10 \%$ & & & $60 \%$ & $40 \%$ & & & $60 \%$ & & & $40 \%$ \\
\hline Other donation & $90 \%$ & $10 \%$ & & & $60 \%$ & $40 \%$ & & & $60 \%$ & & & $40 \%$ \\
\hline Returned to seller after lease expired & $90 \%$ & $10 \%$ & & & $70 \%$ & $30 \%$ & & & $70 \%$ & & & Bo\% \\
\hline Sold online (e.g. eBay) & $90 \%$ & $10 \%$ & & & $70 \%$ & $30 \%$ & & & $70 \%$ & & & Bo\% \\
\hline Sold locally & $90 \%$ & $10 \%$ & & & $70 \%$ & $30 \%$ & & & $70 \%$ & & & $30 \%$ \\
\hline Sold to an acquaintance/friend/family & $90 \%$ & $10 \%$ & & & $80 \%$ & $20 \%$ & & & $80 \%$ & & & $20 \%$ \\
\hline Other & & & & $100 \%$ & & & & $100 \%$ & & & & $100 \%$ \\
\hline
\end{tabular}

Figure S15: Comparison of User's Intended End-of-Use Activity and Actual End-of-Use Path for Three Scenarios. Width of Bar Represents Percentage Allotted.

\subsection{SSUM Generation}

The 2010 Scale Factors (SF) relating the survey values to the national statistics were found are shown below.

\begin{tabular}{|lrrr|}
\hline \multicolumn{2}{|c|}{ Table S4: Summary of } & 2010 Scale Factors by Sector \\
\hline Sector & Mean & Low & High \\
\hline Business/Public & 799 & 726 & 873 \\
\hline Residential & 87,496 & 84,620 & 90,552 \\
\hline
\end{tabular}

\subsubsection{Residential Scale Factors}

To calculate the residential SFs over time shown in Table S5, the computer-owning residents represented by the survey in a given year were compared to the computer-owning residents nationally. If from the survey responses we could infer that a respondent had a computer in the household in a given year, the number of residents in the household were included in that sum. For survey responses about stock $+/-$ $3 \%$ was assigned to 2010 estimates and $+/-10 \%$ was assigned to prior years since the respondents are not nationally representative of prior years.

In order to estimate the number of computer owning residents nationally in a given year, we multiplied the Civilian Non-Institutionalized Population[8,9] by the percent of households owning desktop and laptop computers from the Census Current Population Survey [10, 11]. Figure S16 shows a logistic curve fit through the percent of households owning desktop and laptop computers; the fit is very good for 
the years of interest. A recommended confidence interval was assigned to the Census Current Population Survey computer ownership estimates based on guidance from the Bureau of Labor Statistics[12].

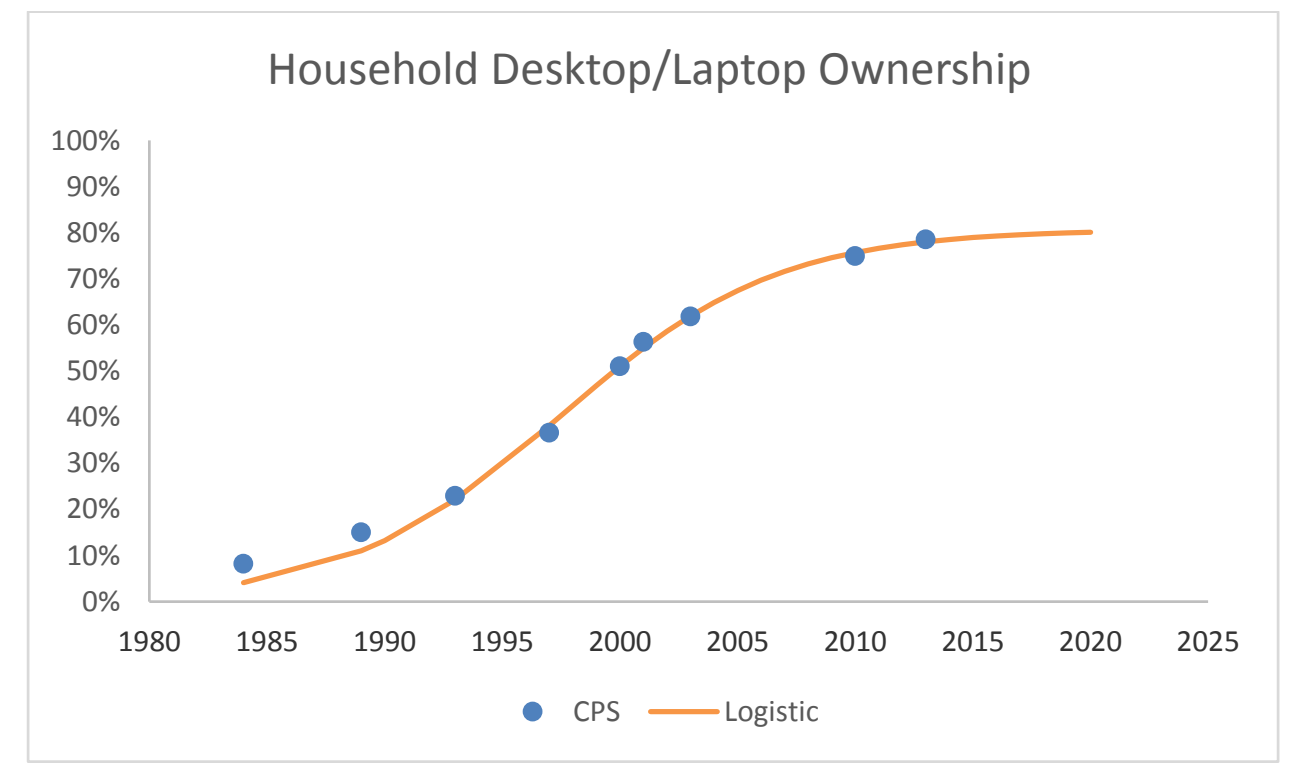

Figure S16: Census Current Population Survey estimates of percent of households with laptop or desktop computer, and logistic curve fit to the data. $X 0=1997.5, k=0.22, L=0.81$.

\begin{tabular}{|rrrr|}
\hline Table S5: Summary of Residential Scale Factors by Year \\
\hline Year & Mean & Low & High \\
\hline $\mathbf{2 0 0 0}$ & 144,390 & 130,706 & 161,115 \\
\hline $\mathbf{2 0 0 1}$ & 143,720 & 130,106 & 160,361 \\
\hline $\mathbf{2 0 0 2}$ & 133,751 & 121,086 & 149,231 \\
\hline $\mathbf{2 0 0 3}$ & 130,558 & 118,200 & 145,664 \\
\hline $\mathbf{2 0 0 4}$ & 122,123 & 110,567 & 136,247 \\
\hline $\mathbf{2 0 0 5}$ & 112,779 & 102,111 & 125,818 \\
\hline $\mathbf{2 0 0 6}$ & 105,496 & 95,521 & 117,688 \\
\hline $\mathbf{2 0 0 7}$ & 101,521 & 91,926 & 113,250 \\
\hline $\mathbf{2 0 0 8}$ & 96,639 & 87,509 & 107,800 \\
\hline $\mathbf{2 0 0 9}$ & 92,269 & 83,554 & 102,922 \\
\hline $\mathbf{2 0 1 0}$ & 87,496 & 84,620 & 90,552 \\
\hline
\end{tabular}

\subsubsection{Business/Public Scale Factors}

For the business/public SF, the low and high scale factors resulted from $+/-10 \%$ uncertainty assigned to sales data and approximately $+/-5 \%$ assigned to survey purchases.

Table S6 below presents the detailed scale factors found for each product and sector, used to arrive at the overall average product scale factors. The CRT monitor scale factor was excluded from the overall average because it is likely erroneous. Recall that the same scale factor was used to scale up each product for a given country and sector. For comparison purposes, a Business/Public Scale Factor based on the number of employees in the facilities of the businesses surveyed was compared with the number of 
employees in the country in 2010. This Employee Scale Factor is likely higher than those based on sales because the survey is only representative of the subset of businesses with computers, while the employee estimate refers to employees in all businesses. Similarly, a scale factor based on US population compared to the people represented by survey respondents' households is compared with the Residential Scale Factor. It is most similar to the Laptop Scale Factor, but certainly higher than all of the products. This could suggest that the sales estimates are too low, or the survey respondents purchase more than the average household.

Table S6: 2010 Business/Public Product Scale Factors Used to Arrive at Overall Product Average Scale Factors

\begin{tabular}{|l|rrrr|}
\hline Sector & Scale Factor Type & Mean & \multicolumn{2}{c}{ Max } \\
\hline Business/Public & 922 & 837 & 1,006 \\
\hline & Lesktop & 1,385 & 1,258 & 1,511 \\
\hline CRT Monitor & 0 & 0 & 0 \\
\hline Flat Panel Monitor & 891 & 809 & 973 \\
\hline All Product Average & 799 & 726 & 873 \\
\hline Product Average, & $\mathbf{1 , 0 6 6}$ & $\mathbf{9 6 8}$ & $\mathbf{1 , 1 6 3}$ \\
& no CRT monitor & & & \\
\hline Employee & 1,878 & 1,706 & 2,050 \\
\hline
\end{tabular}




\section{Results}

\subsection{Lifespan Distributions}

Table S7 presents this study's estimated distribution of residential possession span, no informal reuse $\lambda$ estimates for desktops, laptops, CRT and flat panel monitors are presented with a solid line. Note the distributions do not incorporate the small fraction of products that were predicted to undergo reuse, because those distributions change slightly over time depending on the predicted future sales which impact reuse likelihood. It also presents the roughly comparable Weibull distributions representing the lifespan until generation developed by UNU for these products in the Netherlands, France, and Belgium[13]. Table S8 provides descriptive statistics for empirical distributions presented in Kwak (2012).

Table S7: Mean Weibull Distribution Parameters for residential possession span, no informal reuse $\lambda$ (this study) and Lifespan (UNU(2015) [13]

\begin{tabular}{|c|c|c|c|c|}
\hline Study & EEE Category & Product & $\begin{array}{l}\text { Weibull } \\
\text { Distribution Scale } \\
\text { Parameter }\end{array}$ & $\begin{array}{l}\text { Weibull } \\
\text { Distribution Shape } \\
\text { Parameter }\end{array}$ \\
\hline This Study & & Desktop & 2.09 & 7.61 \\
\hline This Study & & Laptop & 1.71 & 13.28 \\
\hline This Study & & CRT Monitor & 2.10 & 7.46 \\
\hline This Study & & $\begin{array}{l}\text { Flat Screen } \\
\text { Monitor }\end{array}$ & 1.77 & 15.05 \\
\hline UNU (2015) & 0302 & Desktop & 2.10 & 9.60 \\
\hline UNU (2015) & 0303 & Laptop & 1.50 & 5.20 \\
\hline UNU (2015) & 0308 & CRT Monitor & 2.20 & 8.50 \\
\hline UNU (2015) & 0309 & $\begin{array}{l}\text { Flat Screen } \\
\text { Monitor }\end{array}$ & 2.50 & 7.50 \\
\hline
\end{tabular}

Table S8: Descriptive statistics of the age (years) and wear-out lifespan for used electronics collected at a drop-off center in Chicago, from Kwak (2012) [14]

\begin{tabular}{|c|c|c|c|c|c|c|c|}
\hline Туре & $\begin{array}{l}\text { Wear- } \\
\text { Out } \\
\text { Lifespan }\end{array}$ & Mean & St dev. & Min. & Median & Max. & IQR \\
\hline Desktop & $5-6$ & 9.16 & 3.05 & 1.92 & 8.82 & 27.72 & 3.04 \\
\hline Laptop & $3-5$ & 11.10 & 3.39 & 3.10 & 10.46 & 26.67 & 3.97 \\
\hline Monitor & $8-10$ & 9.95 & 3.24 & 1.24 & 9.48 & 29.44 & 4.03 \\
\hline
\end{tabular}




\subsection{SOM and SSUM Results}

The following tables, Table S9 through Table S13, provide quantity and weight estimates for both methods in the study.

\subsubsection{SOM (Residential only)}

Table S9: SOM Quantity of United States Generation and Collection of Used Computers and Monitors in 2010. Mean, Low and High Bounds Of 95\% Confidence Interval (Thousand Units)

\begin{tabular}{|c|c|c|c|c|c|c|c|c|c|c|}
\hline \multirow[t]{2}{*}{ Product } & \multirow[t]{2}{*}{ Flows } & \multicolumn{3}{|c|}{ Residential } & \multicolumn{3}{|c|}{ Business/Public* } & \multicolumn{3}{|c|}{ Total } \\
\hline & & Mean & Low & High & Mean & Low & High & Mean & Low & High \\
\hline \multirow[t]{2}{*}{ Desktop } & Generated & 14,385 & 12,823 & 16,049 & & & & & & \\
\hline & Collected & 10,181 & 8,322 & 12,249 & & & & & & \\
\hline \multirow[t]{2}{*}{ Laptop } & Generated & 3,728 & 2,203 & 5,627 & & & & & & \\
\hline & Collected & 2,727 & 1,575 & 4,243 & & & & & & \\
\hline \multirow[t]{2}{*}{ Computer } & Generated & 18,113 & 15,673 & 20,843 & & & & & & \\
\hline & Collected & 12,908 & 10,346 & 15,817 & & & & & & \\
\hline \multirow{2}{*}{$\begin{array}{c}\text { CRT } \\
\text { Monitors }\end{array}$} & Generated & 7,485 & 4,631 & 11,188 & & & & & & \\
\hline & Collected & 5,122 & 3,081 & 7,864 & & & & & & \\
\hline \multirow{2}{*}{$\begin{array}{l}\text { Flat Panel } \\
\text { Monitors }\end{array}$} & Generated & 2,953 & 1,690 & 4,596 & & & & & & \\
\hline & Collected & 2,020 & 1,115 & 3,224 & & & & & & \\
\hline \multirow[t]{2}{*}{ Monitor } & Generated & 10,439 & 7,007 & 14,615 & & & & & & \\
\hline & Collected & 7,142 & 4,629 & 10,397 & & & & & & \\
\hline
\end{tabular}

Table S10: SOM Weight of United States Generation, Collection, and Export Of Used Computers and Monitors in 2010. Mean, Low and High Bounds of 95\% Confidence Interval (Thousand Metric Tons)

\begin{tabular}{|clcccc|c|}
\hline \multirow{2}{*}{ Product } & Flows & \multicolumn{3}{c}{ Residential } & Business/Public* & Total \\
\hline \multirow{2}{*}{ Desktop } & Generated & 153 & 66 & 289 & \\
& Collected & 108 & 43 & 221 & How \\
\cline { 2 - 6 } Laptop & Generated & 11 & 3 & 38 \\
& Collected & 8 & 2 & 29 \\
\hline Computer & Generated & 164 & 68 & 328 \\
\cline { 2 - 7 } & Collected & 116 & 45 & 250 \\
\hline CRT & Generated & 117 & 48 & 252 \\
Monitors & Collected & 80 & 32 & 177 \\
\hline Flat Panel & Generated & 36 & 4 & 159 \\
Monitors & Collected & 25 & 3 & 111 \\
\hline Monitor & Generated & 153 & 52 & 411 \\
& Collected & 105 & 35 & 288 \\
\hline
\end{tabular}

*, Only conducted by SSUM methods. 


\subsubsection{SSUM}

Table S11: SSUM Quantity of United States Generation and Collection Used Computers and Monitors in 2010. Mean, Low and High Bounds of 95\% Confidence Interval (Thousand Units)

\begin{tabular}{|c|c|c|c|c|c|c|c|c|c|c|}
\hline \multirow[t]{2}{*}{ Product } & \multirow[t]{2}{*}{ Flows } & \multicolumn{3}{|c|}{ Residential } & \multicolumn{3}{|c|}{ Business/Public } & \multicolumn{3}{|c|}{ Total } \\
\hline & & Mean & Low & High & Mean & Low & High & Mean & Low & High \\
\hline \multirow[t]{2}{*}{ Desktop } & Generated & 10,769 & 10,408 & 11,138 & 14,272 & 12,962 & 15,578 & 25,041 & 23,371 & 26,716 \\
\hline & Collected & 9,018 & 9,054 & 9,327 & 10,181 & 9,990 & 11,113 & 19,200 & 19,045 & 20,440 \\
\hline \multirow[t]{2}{*}{ Laptop } & Generated & 5,166 & 4,993 & 5,343 & 8,712 & 7,912 & 9,509 & 13,877 & 12,905 & 14,852 \\
\hline & Collected & 4,640 & 4,586 & 4,799 & 6,790 & 6,516 & 7,412 & 11,431 & 11,103 & 12,211 \\
\hline \multirow[t]{2}{*}{ Computer } & Generated & 15,935 & 15,401 & 16,480 & 22,983 & 20,875 & 25,087 & 38,919 & 36,276 & 41,568 \\
\hline & Collected & 13,659 & 13,641 & 14,126 & 16,971 & 16,507 & 18,525 & 30,630 & 30,147 & 32,651 \\
\hline \multirow{2}{*}{$\begin{array}{c}\text { CRT } \\
\text { Monitor }\end{array}$} & Generated & 6,304 & 6,093 & 6,520 & 9,953 & 9,040 & 10,864 & 16,257 & 15,133 & 17,384 \\
\hline & Collected & 5,516 & 5,483 & 5,705 & 9,314 & 8,576 & 10,166 & 14,830 & 14,059 & 15,871 \\
\hline \multirow{2}{*}{$\begin{array}{l}\text { Flat Panel } \\
\text { Monitor }\end{array}$} & Generated & 2,364 & 2,285 & 2,445 & 5,992 & 5,442 & 6,540 & 8,356 & 7,727 & 8,985 \\
\hline & Collected & 1,576 & 1,675 & 1,630 & 2,782 & 3,110 & 3,036 & 4,358 & 4,785 & 4,666 \\
\hline \multirow[t]{2}{*}{ Monitor } & Generated & 8,668 & 8,377 & 8,965 & 15,945 & 14,482 & 17,405 & 24,613 & 22,860 & 26,369 \\
\hline & Collected & 7,092 & 7,159 & 7,335 & 12,096 & 11,685 & 13,203 & 19,188 & 18,844 & 20,537 \\
\hline
\end{tabular}

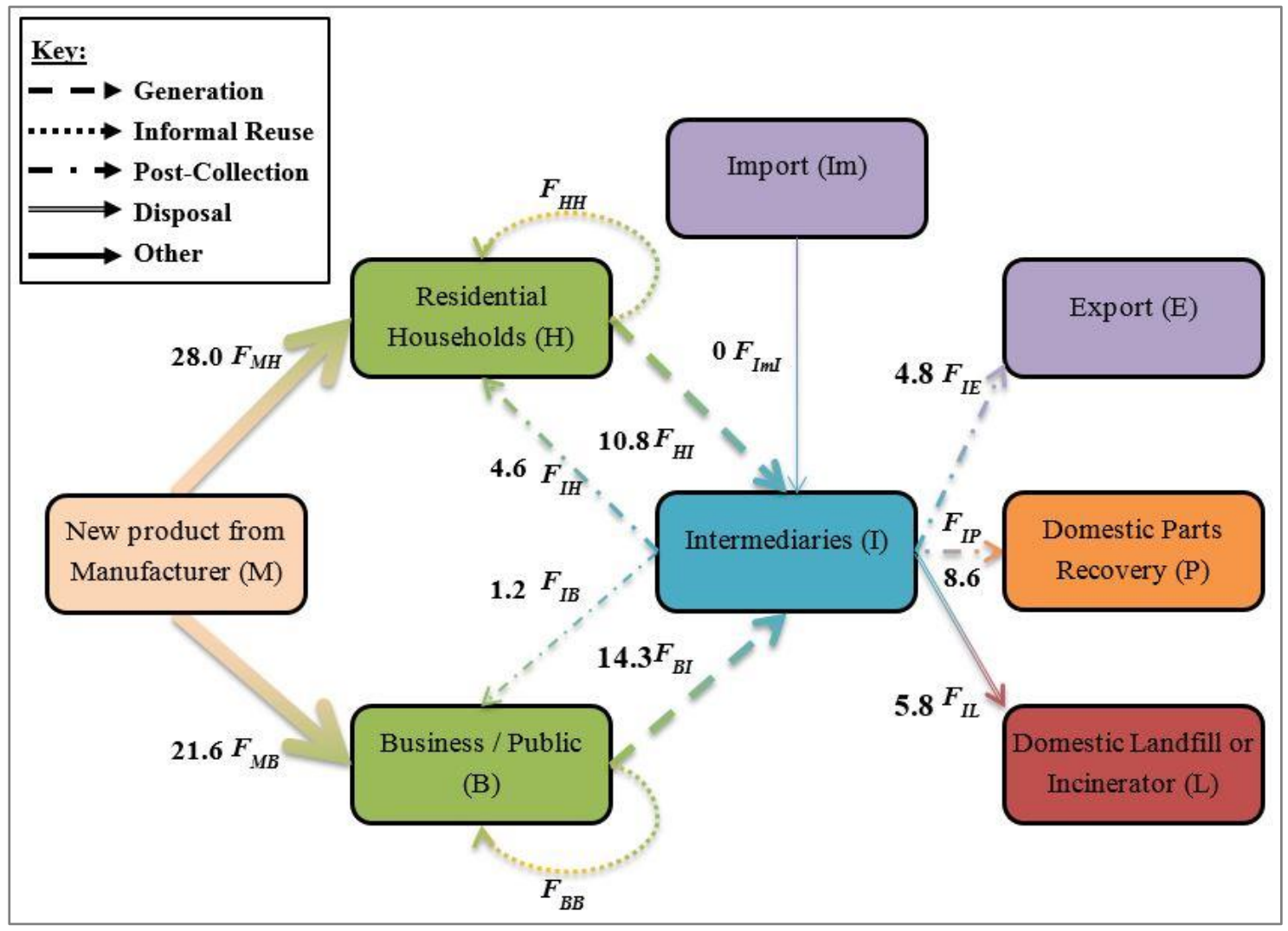

Figure S17: SSUM 2010 Desktop flows, mean of intended reuse scenario. Millions of desktops. 
Table S12: SSUM Quantity (thousands of units) of US Flows Quantified in SSUM Method. Flows pertain to Figure 2 in text.

Note: Flows (F) are from manufacturer (M) through residential households (H) and business/public (B) users, to intermediaries (I). Intermediaries also collect used imports (Im), and either redistribute them for reuse to households $(\mathrm{H})$ and business/public (B) users, send them to the landfill or incinerator (L), sell them domestically for parts and materials recycling $(\mathrm{R})$, or export them to a foreign country $(\mathrm{E})$. The ordering of indices is from/to, i.e. FHI refers to flows from Residential Households (H) to intermediary (I) and $\mathrm{F}_{\mathrm{IH}}$ refers to flows from intermediary (I) to Residential Households $(\mathrm{H})$.

\begin{tabular}{|c|c|c|c|c|c|c|c|c|c|c|}
\hline \multirow[t]{2}{*}{ Product } & \multirow[t]{2}{*}{ Flows } & \multicolumn{3}{|c|}{$\begin{array}{l}\text { Intended End-of-Use } \\
\text { Scenario }\end{array}$} & \multicolumn{3}{|c|}{ Lower Reuse Scenario } & \multicolumn{3}{|c|}{ Higher Export Scenario } \\
\hline & & Mean & Low & High & Mean & Low & High & Mean & Low & High \\
\hline \multirow[t]{14}{*}{ Desktops } & FMH & 27,999 & 27,078 & 28,977 & 27,999 & 27,078 & 28,977 & 27,999 & 27,078 & 28,977 \\
\hline & FMB & 21,662 & 19,671 & 23,640 & 21,662 & 19,671 & 23,640 & 21,662 & 19,671 & 23,640 \\
\hline & FHI & 10,762 & 10,408 & 11,138 & 10,762 & 10,408 & 11,138 & 10,762 & 10,408 & 11,138 \\
\hline & FBI & 14,275 & 12,962 & 15,578 & 14,275 & 12,962 & 15,578 & 14,275 & 12,962 & 15,578 \\
\hline & FIH & 4,462 & 4,316 & 4,618 & 4,462 & 4,316 & 4,618 & 4,462 & 4,316 & 4,618 \\
\hline & FIB & 1,208 & 1,097 & 1,318 & 1,208 & 1,097 & 1,318 & 1,208 & 1,097 & 1,318 \\
\hline & FIP & 8,653 & 8,150 & 9,165 & 12,838 & 12,043 & 13,644 & 5,951 & 5,614 & 6,294 \\
\hline & FHR & 4,944 & 4,781 & 5,116 & 6,510 & 6,296 & 6,737 & 3,552 & 3,436 & 3,676 \\
\hline & FBR & 3,710 & 3,369 & 4,048 & 6,329 & 5,747 & 6,907 & 2,399 & 2,178 & 2,618 \\
\hline & FIL & 5,841 & 5,408 & 6,276 & 4,673 & 4,326 & 5,021 & 5,841 & 5,408 & 6,276 \\
\hline & FHL & 1,750 & 1,692 & 1,811 & 1,400 & 1,354 & 1,449 & 1,750 & 1,692 & 1,811 \\
\hline & FBL & 4,091 & 3,715 & 4,465 & 3,273 & 2,972 & 3,572 & 4,091 & 3,715 & 4,465 \\
\hline & FIMI & 0 & 0 & 0 & 0 & 0 & 0 & 0 & 0 & 0 \\
\hline & FIE & 4,872 & 4,401 & 5,339 & 1,855 & 1,590 & 2,115 & 7,574 & 6,937 & 8,209 \\
\hline \multirow[t]{14}{*}{ Laptops } & FMH & 13,912 & 13,455 & 14,398 & 13,912 & 13,455 & 14,398 & 13,912 & 13,455 & 14,398 \\
\hline & FMB & 12,746 & 11,574 & 13,910 & 12,746 & 11,574 & 13,910 & 12,746 & 11,574 & 13,910 \\
\hline & FHI & 5,162 & 4,993 & 5,343 & 5,162 & 4,993 & 5,343 & 5,162 & 4,993 & 5,343 \\
\hline & FBI & 8,713 & 7,912 & 9,509 & 8,713 & 7,912 & 9,509 & 8,713 & 7,912 & 9,509 \\
\hline & FIH & 1,837 & 1,777 & 1,902 & 1,837 & 1,777 & 1,902 & 1,837 & 1,777 & 1,902 \\
\hline & FIB & 805 & 731 & 878 & 805 & 731 & 878 & 805 & 731 & 878 \\
\hline & FIP & 4,071 & 3,837 & 4,309 & 6,381 & 5,974 & 6,792 & 2,623 & 2,483 & 2,766 \\
\hline & FHR & 2,371 & 2,293 & 2,454 & 3,036 & 2,936 & 3,142 & 1,715 & 1,659 & 1,775 \\
\hline & FBR & 1,700 & 1,544 & 1,855 & 3,345 & 3,037 & 3,650 & 908 & 825 & 991 \\
\hline & FIL & 2,447 & 2,253 & 2,641 & 1,958 & 1,802 & 2,113 & 2,447 & 2,253 & 2,641 \\
\hline & FHL & 525 & 508 & 543 & 420 & 406 & 435 & 525 & 508 & 543 \\
\hline & FBL & 1,922 & 1,745 & 2,097 & 1,538 & 1,396 & 1,678 & 1,922 & 1,745 & 2,097 \\
\hline & FIMI & 0 & 0 & 0 & 0 & 0 & 0 & 0 & 0 & 0 \\
\hline & FIE & 4,715 & 4,307 & 5,122 & 2,895 & 2,621 & 3,167 & 6,163 & 5,661 & 6,665 \\
\hline \multirow{7}{*}{$\begin{array}{l}\text { CRT } \\
\text { Monitors }\end{array}$} & FMH & 525 & 508 & 543 & 525 & 508 & 543 & 525 & 508 & 543 \\
\hline & FMB & 1,609 & 1,461 & 1,755 & 1,609 & 1,461 & 1,755 & 1,609 & 1,461 & 1,755 \\
\hline & FHI & 6,300 & 6,093 & 6,520 & 6,300 & 6,093 & 6,520 & 6,300 & 6,093 & 6,520 \\
\hline & FBI & 9,955 & 9,040 & 10,864 & 9,955 & 9,040 & 10,864 & 9,955 & 9,040 & 10,864 \\
\hline & FIH & 787 & 762 & 815 & 787 & 762 & 815 & 787 & 762 & 815 \\
\hline & FIB & 403 & 366 & 440 & 403 & 366 & 440 & 403 & 366 & 440 \\
\hline & FIP & 5,641 & 5,304 & 5,983 & 8,544 & 8,002 & 9,091 & 3,663 & 3,456 & 3,873 \\
\hline
\end{tabular}




\begin{tabular}{|c|c|c|c|c|c|c|c|c|c|c|}
\hline \multirow[t]{2}{*}{ Product } & \multirow[t]{2}{*}{ Flows } & \multicolumn{3}{|c|}{$\begin{array}{l}\text { Intended End-of-Use } \\
\text { Scenario }\end{array}$} & \multicolumn{3}{|c|}{ Lower Reuse Scenario } & \multicolumn{3}{|c|}{ Higher Export Scenario } \\
\hline & & Mean & Low & High & Mean & Low & High & Mean & Low & High \\
\hline \multirow{21}{*}{$\begin{array}{l}\text { Flat Panel } \\
\text { Monitors }\end{array}$} & FHR & 3,071 & 2,970 & 3,178 & 4,130 & 3,994 & 4,274 & 2,205 & 2,132 & 2,282 \\
\hline & FBR & 2,570 & 2,334 & 2,805 & 4,414 & 4,008 & 4,817 & 1,458 & 1,324 & 1,591 \\
\hline & FIL & 1,427 & 1,342 & 1,513 & 1,142 & 1,074 & 1,210 & 1,427 & 1,342 & 1,513 \\
\hline & FHL & 787 & 762 & 815 & 630 & 609 & 652 & 787 & 762 & 815 \\
\hline & FBL & 640 & 581 & 698 & 512 & 465 & 558 & 640 & 581 & 698 \\
\hline & FIMI & 0 & 0 & 0 & 0 & 0 & 0 & 0 & 0 & 0 \\
\hline & FIE & 7,996 & 7,359 & 8,633 & 5,379 & 4,929 & 5,828 & 9,975 & 9,206 & 10,743 \\
\hline & FMH & 15,837 & 15,316 & 16,390 & 15,837 & 15,316 & 16,390 & 15,837 & 15,316 & 16,390 \\
\hline & FMB & 22,450 & 20,386 & 24,500 & 22,450 & 20,386 & 24,500 & 22,450 & 20,386 & 24,500 \\
\hline & FHI & 2,362 & 2,285 & 2,445 & 2,362 & 2,285 & 2,445 & 2,362 & 2,285 & 2,445 \\
\hline & FBI & 5,993 & 5,442 & 6,540 & 5,993 & 5,442 & 6,540 & 5,993 & 5,442 & 6,540 \\
\hline & FIH & 2,800 & 2,708 & 2,898 & 2,800 & 2,708 & 2,898 & 2,800 & 2,708 & 2,898 \\
\hline & FIB & 2,057 & 1,868 & 2,245 & 2,057 & 1,868 & 2,245 & 2,057 & 1,868 & 2,245 \\
\hline & FIP & 1,887 & 1,760 & 2,014 & 3,368 & 3,125 & 3,612 & 1,275 & 1,190 & 1,360 \\
\hline & FHR & 787 & 762 & 815 & 1,129 & 1,092 & 1,168 & 551 & 533 & 570 \\
\hline & FBR & 1,099 & 998 & 1,200 & 2,240 & 2,034 & 2,444 & 724 & 657 & 790 \\
\hline & FIL & 3,998 & 3,677 & 4,319 & 3,199 & 2,942 & 3,455 & 3,998 & 3,677 & 4,319 \\
\hline & FHL & 787 & 762 & 815 & 630 & 609 & 652 & 787 & 762 & 815 \\
\hline & FBL & 3,211 & 2,916 & 3,504 & 2,569 & 2,332 & 2,803 & 3,211 & 2,916 & 3,504 \\
\hline & FIMI & 2,450 & 2,343 & 2,560 & 3,132 & 2,973 & 3,294 & 3,132 & 2,973 & 3,294 \\
\hline & FIE & 63 & 57 & 69 & 63 & 57 & 69 & 1,356 & 1,257 & 1,457 \\
\hline
\end{tabular}

Table S13: SSUM Weight of United States Generation, Collection, of Used Computers and Monitors in 2010. Mean, Low and High Bounds Of 95\% Confidence Interval (Thousand Metric Tons)

\begin{tabular}{|c|c|c|c|c|c|c|c|c|c|c|}
\hline \multirow[t]{2}{*}{ Product } & & \multicolumn{3}{|c|}{ Residential } & \multicolumn{3}{|c|}{ Business/Public } & \multicolumn{3}{|c|}{ Total } \\
\hline & & Mean & Low & High & Mean & Low & High & Mean & Low & High \\
\hline \multirow[t]{2}{*}{ Desktop } & Generated & 114.3 & 53.3 & 200.8 & 151.5 & 66.4 & 280.9 & 265.7 & 119.7 & 481.7 \\
\hline & Collected & 95.7 & 46.4 & 168.2 & 108.0 & 51.2 & 200.4 & 203.8 & 97.5 & 368.6 \\
\hline \multirow[t]{2}{*}{ Laptop } & Generated & 15.9 & 6.3 & 36.5 & 26.9 & 9.9 & 65.0 & 42.8 & 16.2 & 101.4 \\
\hline & Collected & 14.3 & 5.8 & 32.8 & 20.9 & 8.2 & 50.6 & 35.2 & 14.0 & 83.4 \\
\hline \multirow{2}{*}{$\begin{array}{c}\text { Total } \\
\text { Computer }\end{array}$} & Generated & 130.2 & 59.6 & 237.3 & 178.3 & 76.3 & 345.8 & 308.5 & 135.9 & 583.2 \\
\hline & Collected & 110.0 & 52.1 & 201.0 & 129.0 & 59.3 & 251.0 & 239.0 & 111.5 & 452.0 \\
\hline \multirow{2}{*}{$\begin{array}{c}\text { CRT } \\
\text { Monitor }\end{array}$} & Generated & 98.6 & 63.0 & 146.9 & 155.7 & 93.5 & 244.8 & 254.4 & 156.6 & 391.7 \\
\hline & Collected & 86.3 & 56.7 & 128.5 & 145.7 & 88.7 & 229.1 & 232.0 & 145.5 & 357.6 \\
\hline \multirow{2}{*}{$\begin{array}{l}\text { Flat panel } \\
\text { Monitor }\end{array}$} & Generated & 29.0 & 5.8 & 84.4 & 73.6 & 13.9 & 225.7 & 102.7 & 19.7 & 310.0 \\
\hline & Collected & 19.4 & 4.3 & 56.2 & 34.2 & 7.9 & 104.8 & 53.5 & 12.2 & 161.0 \\
\hline \multirow{2}{*}{$\begin{array}{c}\text { Total } \\
\text { Monitor }\end{array}$} & Generated & 127.7 & 68.9 & 231.3 & 229.4 & 107.4 & 470.5 & 357.0 & 176.2 & 701.7 \\
\hline & Collected & 105.7 & 61.0 & 184.8 & 179.9 & 96.6 & 333.8 & 285.6 & 157.6 & 518.6 \\
\hline
\end{tabular}




\subsubsection{SOM and SSUM compared}

The quantity estimates are compared in Figure 4 in the text; the figure below additionally incorporates unit weight distributions to estimate the aggregate weights.

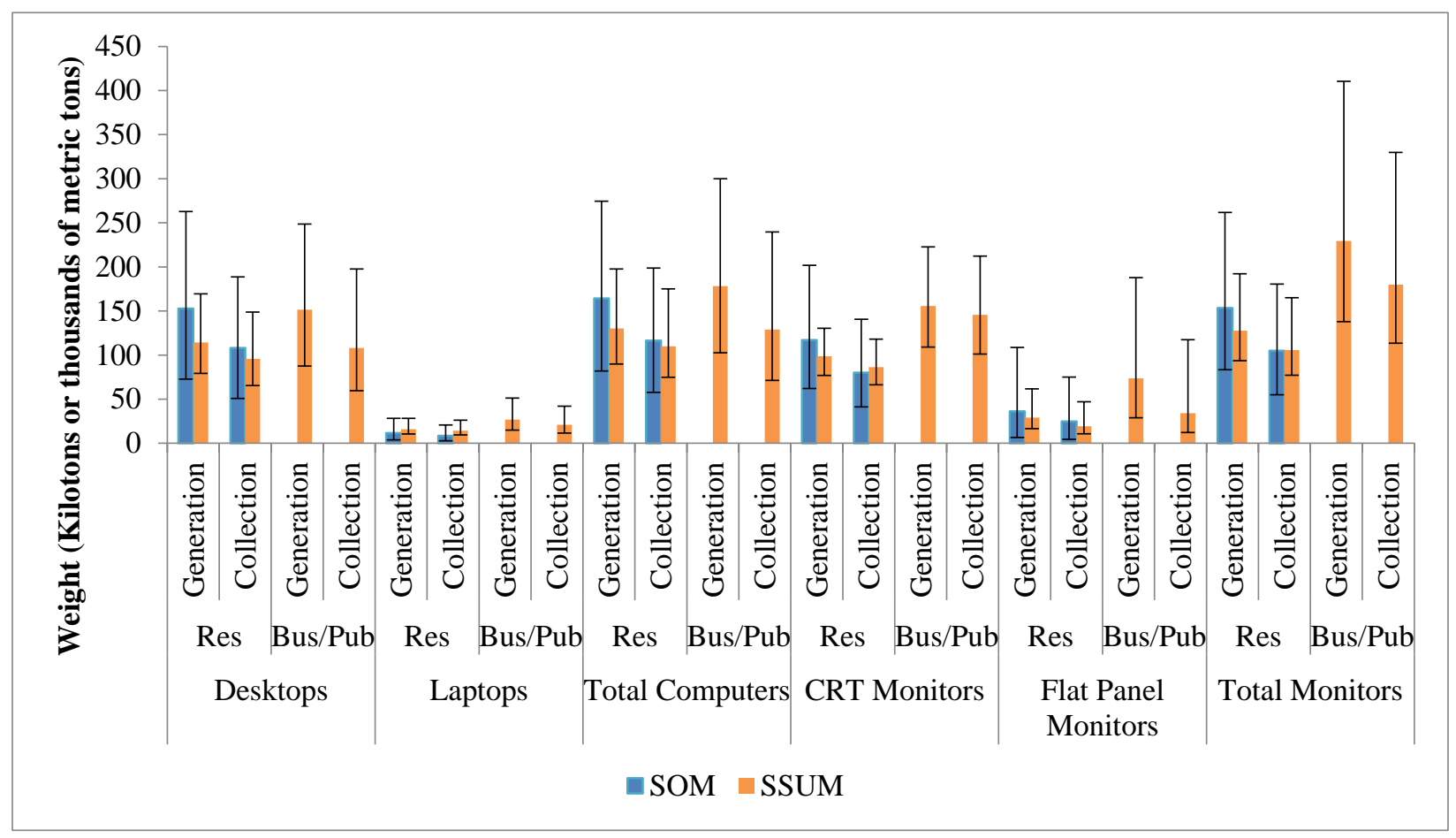

Figure S18: Comparison of 2010 US generation and collection weight in thousands of metric tons (KT) by product, residential sector (Res) and business/public sector (Bus/Pub), and method (SOM or SSUM). Columns represent mean values and error bars represent $95 \%$ confidence interval. 


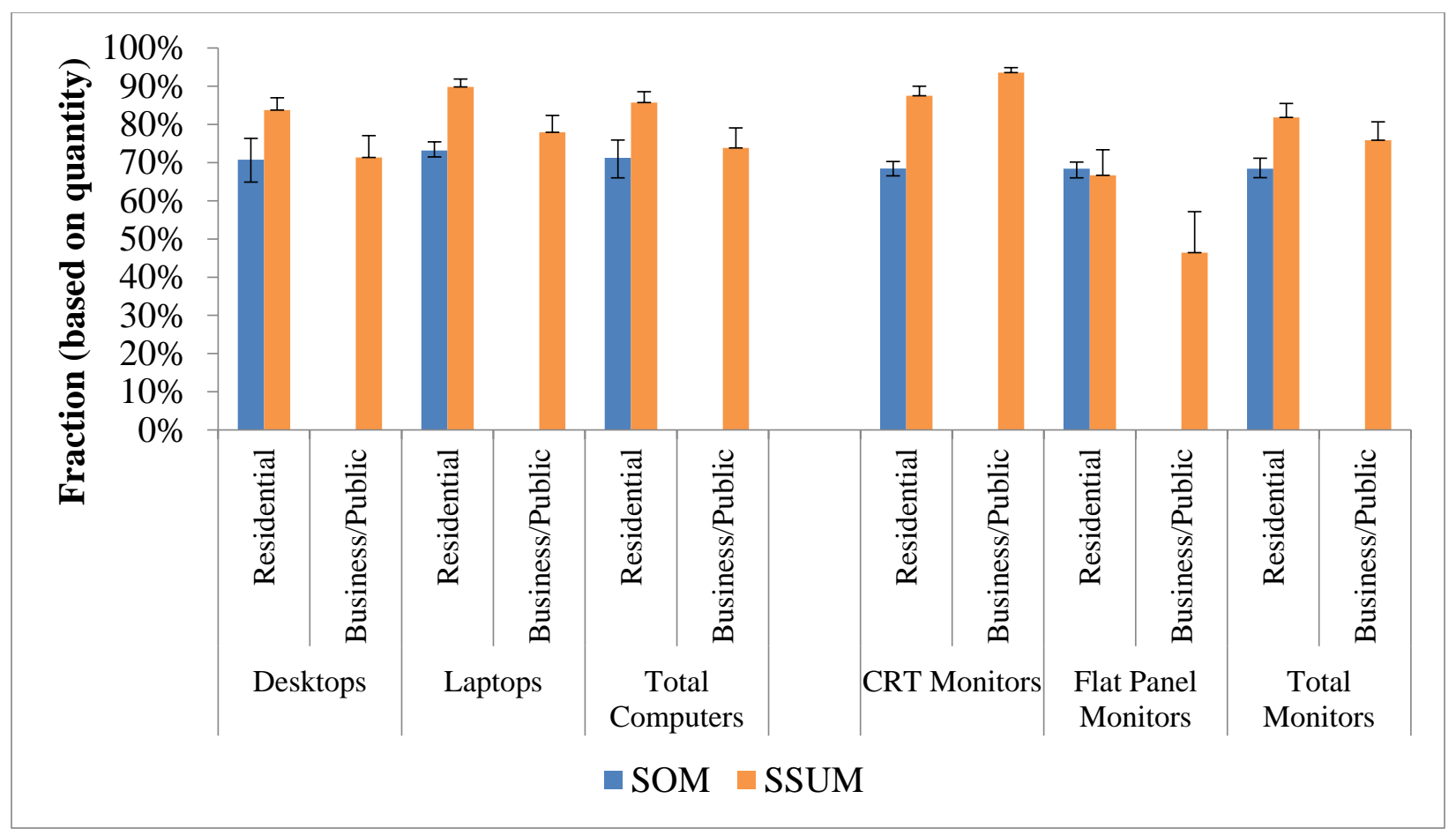

Figure S19: Comparison of 2010 US collection rate calculated from quantity by product, residential sector and business/public sector (SSUM only), and method. Columns represent mean values and error bars represent $95 \%$ confidence interval.

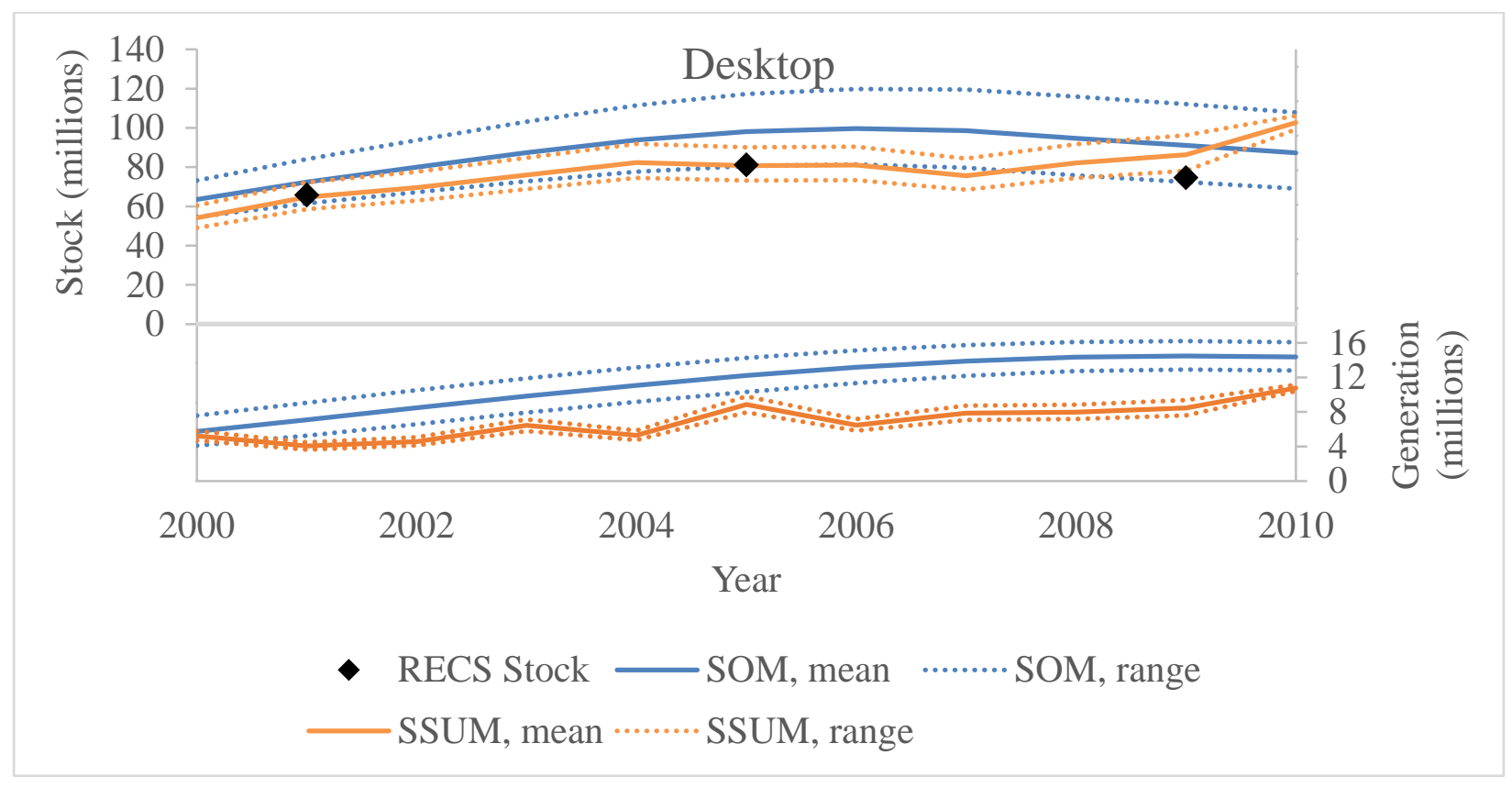

Figure S20: Desktop residential stock (upper) and generation (lower) estimates from 2000 to 2010 as calculated by the SOM and SSUM. Range represents $95^{\text {th }}$ CI for SOM and minimum and maximum for SSUM. Comparison stock data calculated from EIA RECS microdata[15]. 


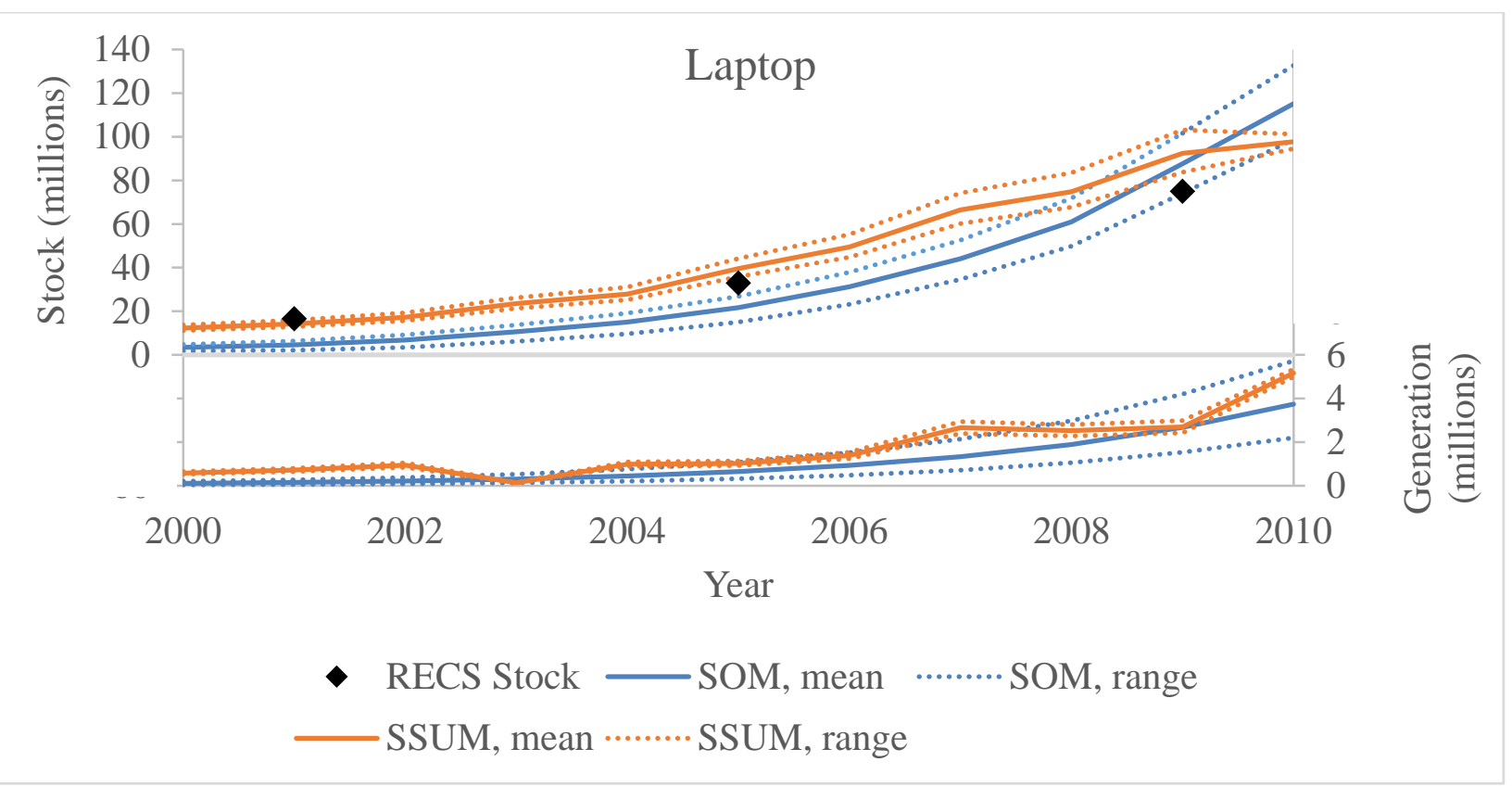

Figure S21: Laptop residential stock (upper) and generation (lower) estimates from 2000 to 2010 as calculated by the SOM and SSUM. Range represents $95^{\text {th }}$ CI for SOM and minimum and maximum for SSUM. Comparison stock data calculated from EIA RECS microdata[15].

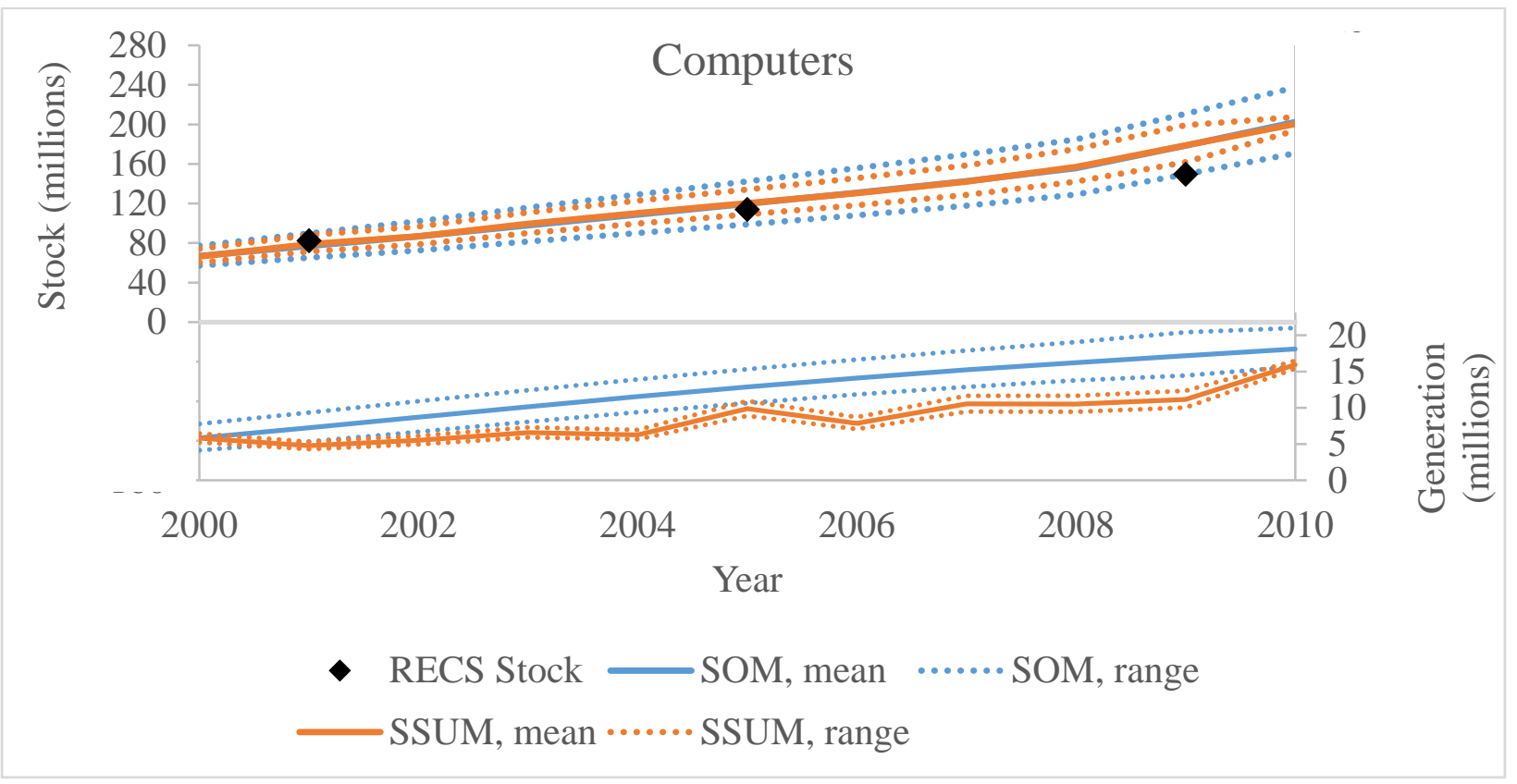

Figure S22: Computer residential stock (upper) and generation (lower) estimates from 2000 to 2010 as calculated by the SOM and SSUM. Range represents $95^{\text {th }}$ CI for SOM and minimum and maximum for SSUM. Comparison stock data calculated from EIA RECS microdata[15]. 


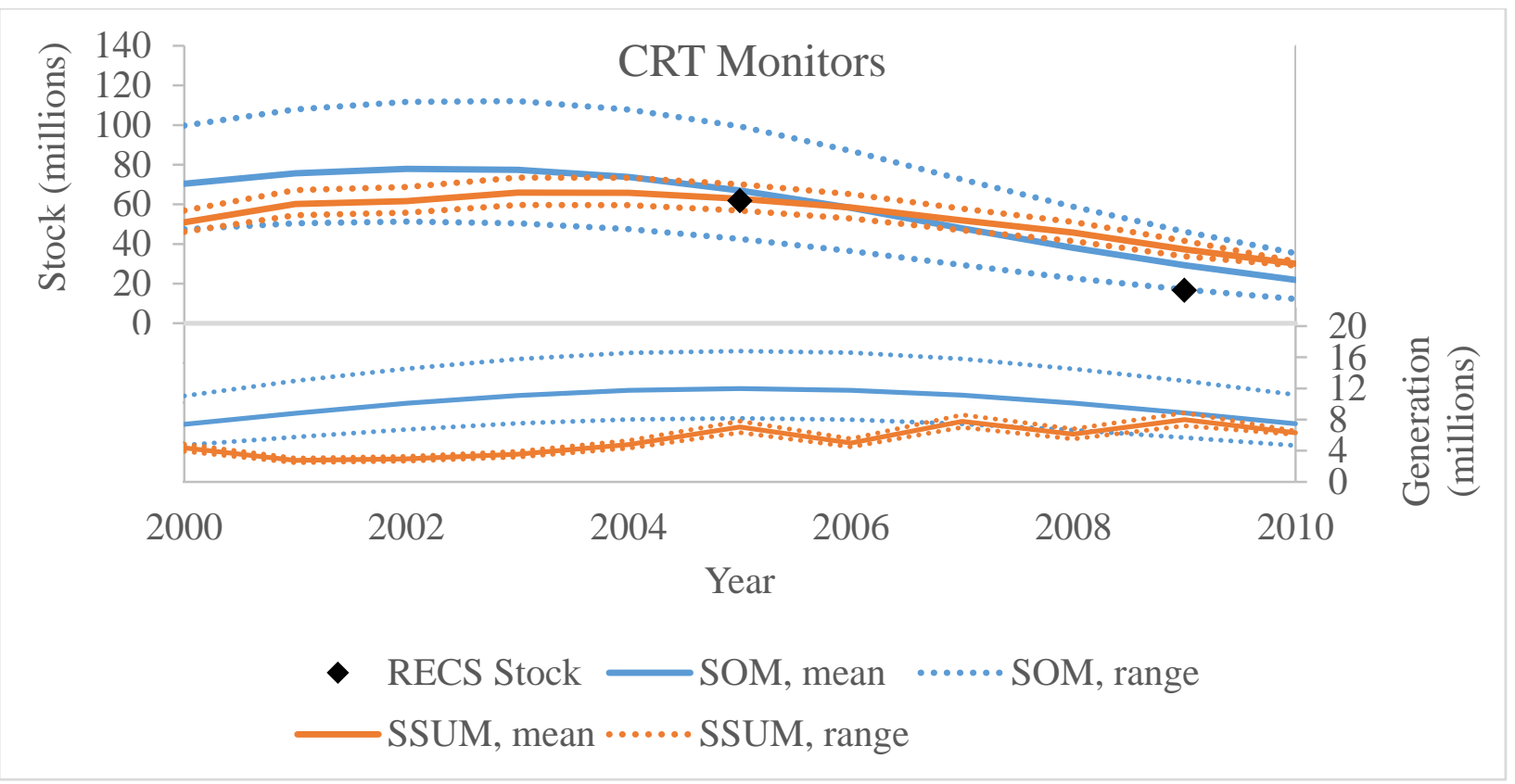

Figure S23: CRT monitors residential stock (upper) and generation (lower) estimates from 2000 to 2010 as calculated by the SOM and SSUM. Range represents $95^{\text {th }}$ CI for SOM and minimum and maximum for SSUM. Comparison stock data calculated from EIA RECS microdata[15].

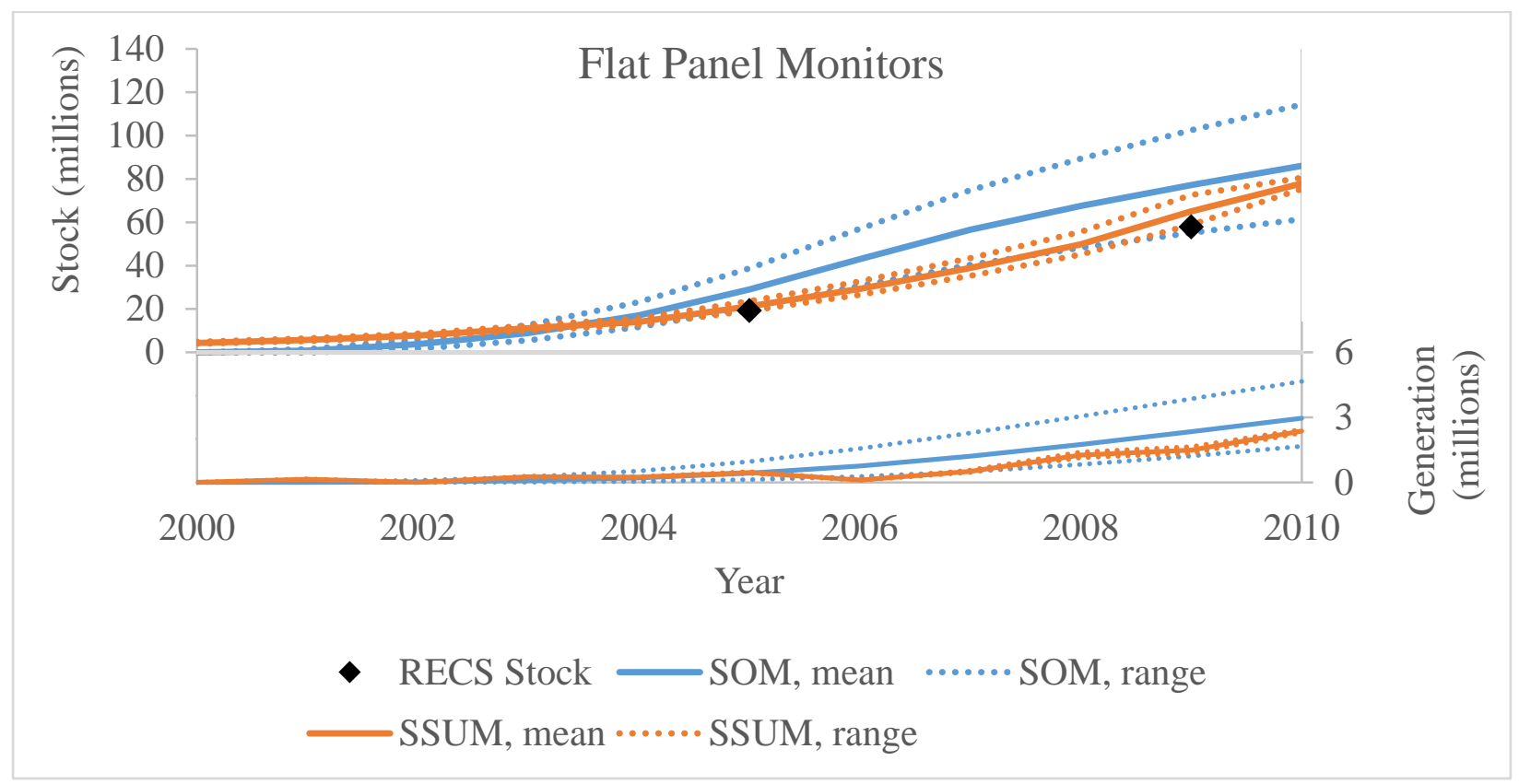

Figure S24: Flat panel monitors residential stock (upper) and generation (lower) estimates from 2000 to 2010 as calculated by the SOM and SSUM. Range represents $95^{\text {th }}$ CI for SOM and minimum and maximum for SSUM. Comparison stock data calculated from EIA RECS microdata[15]. 


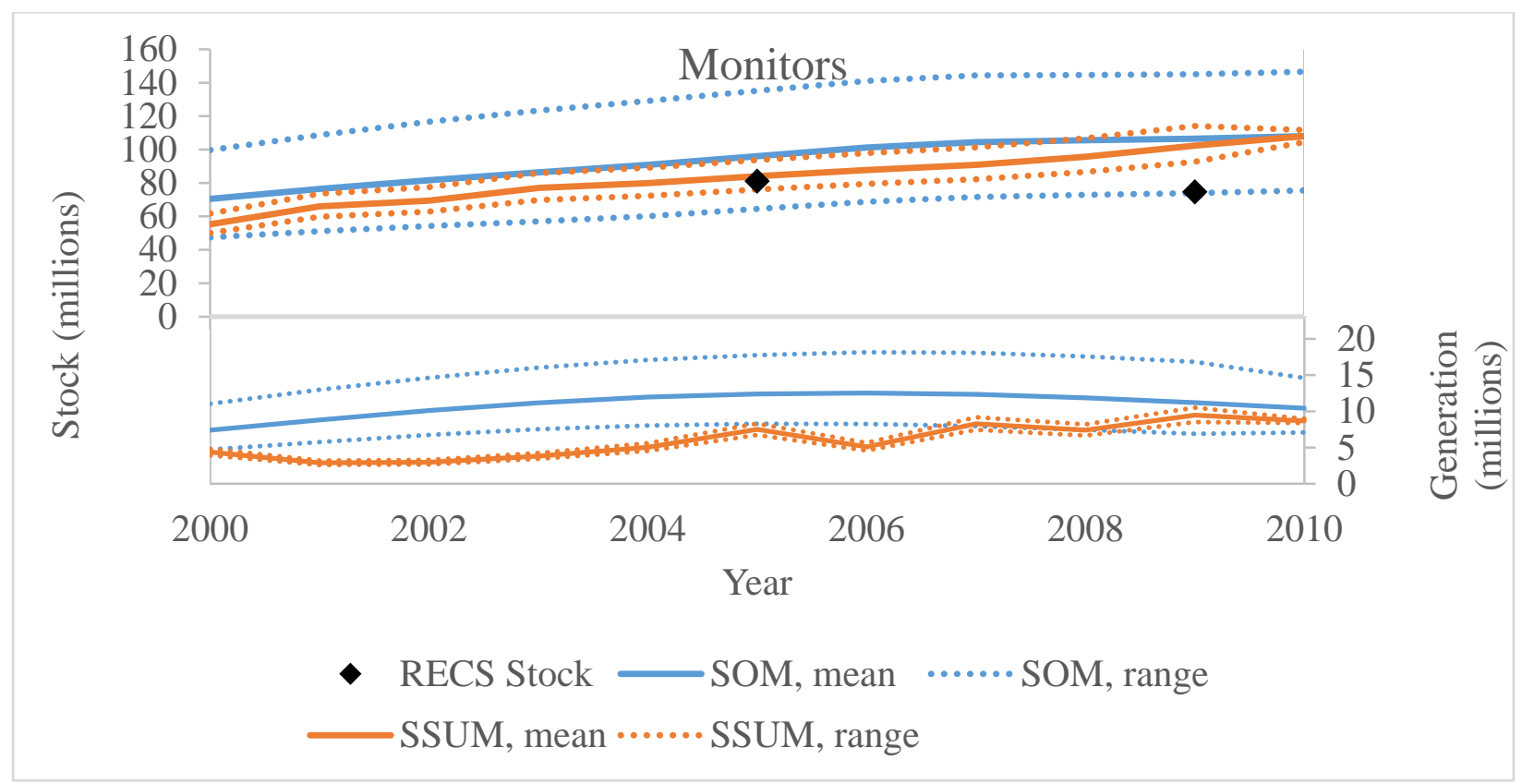

Figure 25: Monitors residential stock (upper) and generation (lower) estimates from 2000 to 2010 as calculated by the SOM and SSUM. Range represents $95^{\text {th }}$ CI for SOM and minimum and maximum for SSUM. Comparison stock data calculated from EIA RECS microdata[15].

\subsubsection{Comparison to Other Sources}

Figure S26 and Figure S27 below and show a comparison of this study's combined residential and business/public SSUM results with two other similar studies. Since the data utilized in this study only supported estimation of residential flows with the SOM, those results were not directly comparable to other studies' estimates of combined flows.

The US EPA has studied the generation and collection of used electronics on several occasions. ICF International, which prepared the 2011 document for the US EPA Office of Resource Conservation and Recovery (US EPA ORCR), used a sales obsolescence method and modeled the year in which an electronic item would be ready for end-of-life management based on the year that it was sold, the year it is expected to become obsolete, and expected storage habits[2]. This is similar to the SOM used in this study, but with less complex lifespans. The 2011 study uses different data than earlier US EPA reports[16, 17]. Differences include that sales data were approximated by manufacturers' shipment data instead of retail and shipment data includes some items which do not have a final sale with a customer. These data were obtained from International Data Corporation (IDC), the Consumer Electronics Association (CEA), and literature. Gartner reports, IDC and literature were used to determine the share of sales in the commercial and residential markets. A 2006 study from the Florida Department of Environmental Protection (DEP) was used in conjunction with industry surveys, expert interviews and literature review to arrive at estimates of residential product lifespans and storage habits. For commercial electronics, they assume that "desktop CPUs, portables, hard-copy devices, and computer monitors are kept in use for three to five years, after which 20 percent are stored for up to two additional years. They believe a two-year storage estimate is conservative, but reflects the fact that commercial businesses are less likely than residential users to store products for long periods of time." Average weight data was determined using Consumer Reports Buying Guides and equipment manufacturer specification sheets.

The 2011 US EPA ORCR study was also used for comparison of collection quantities. It used data from states with used electronics recycling programs to estimate the share of residential generated 
electronics that are collected for processing versus disposal; low collection rates (one pound collected per capita) were assumed for states without programs. A survey of recyclers suggested that two-thirds of collected electronics originated from commercial sources; since the California state program was inclusive of businesses, the residential figure was back-calculated accounting for the two-thirds figure. An overall electronics collection rate of $27 \%$ (by weight) is projected for 2010; the projected computer collection rate is $40 \%$. The authors recognize "considerable uncertainty" in this estimate[2].

Daoud (2011) conducted a representative survey of 182 US electronics recyclers regarding practices in 2010 [18]. Estimates of recycling industry input weight were made for each product. Additionally, the survey asked about the source of recycling input, residential versus business/public, so comparisons to this study's results were made.

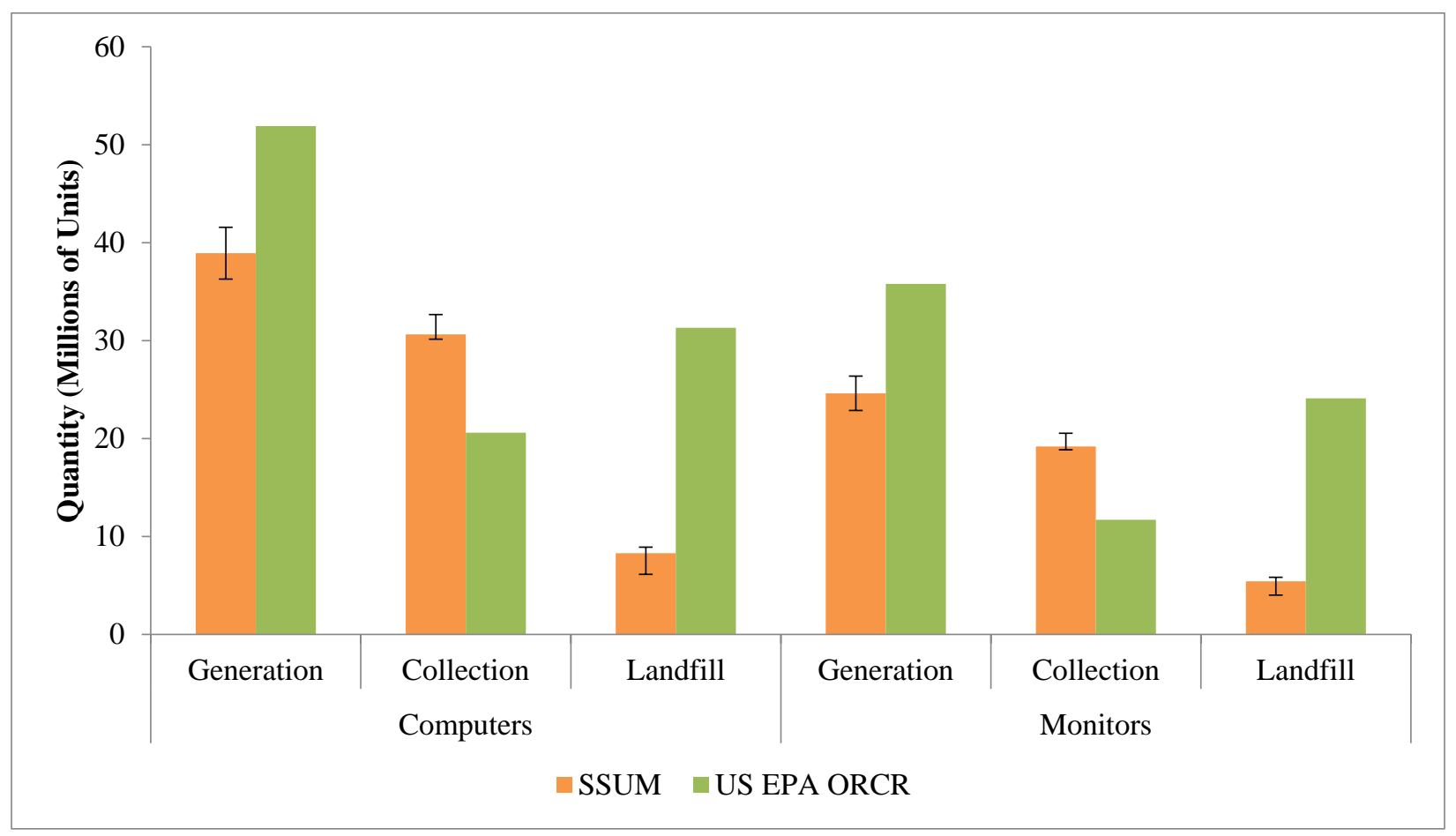

Figure S26:Comparison of total US Generation (Gen), Collection (Coll), and Landfill Quantity By Product and Method with Estimates from US EPA OCRC[2]. Columns represent mean and error bars represent 95\% confidence interval. 


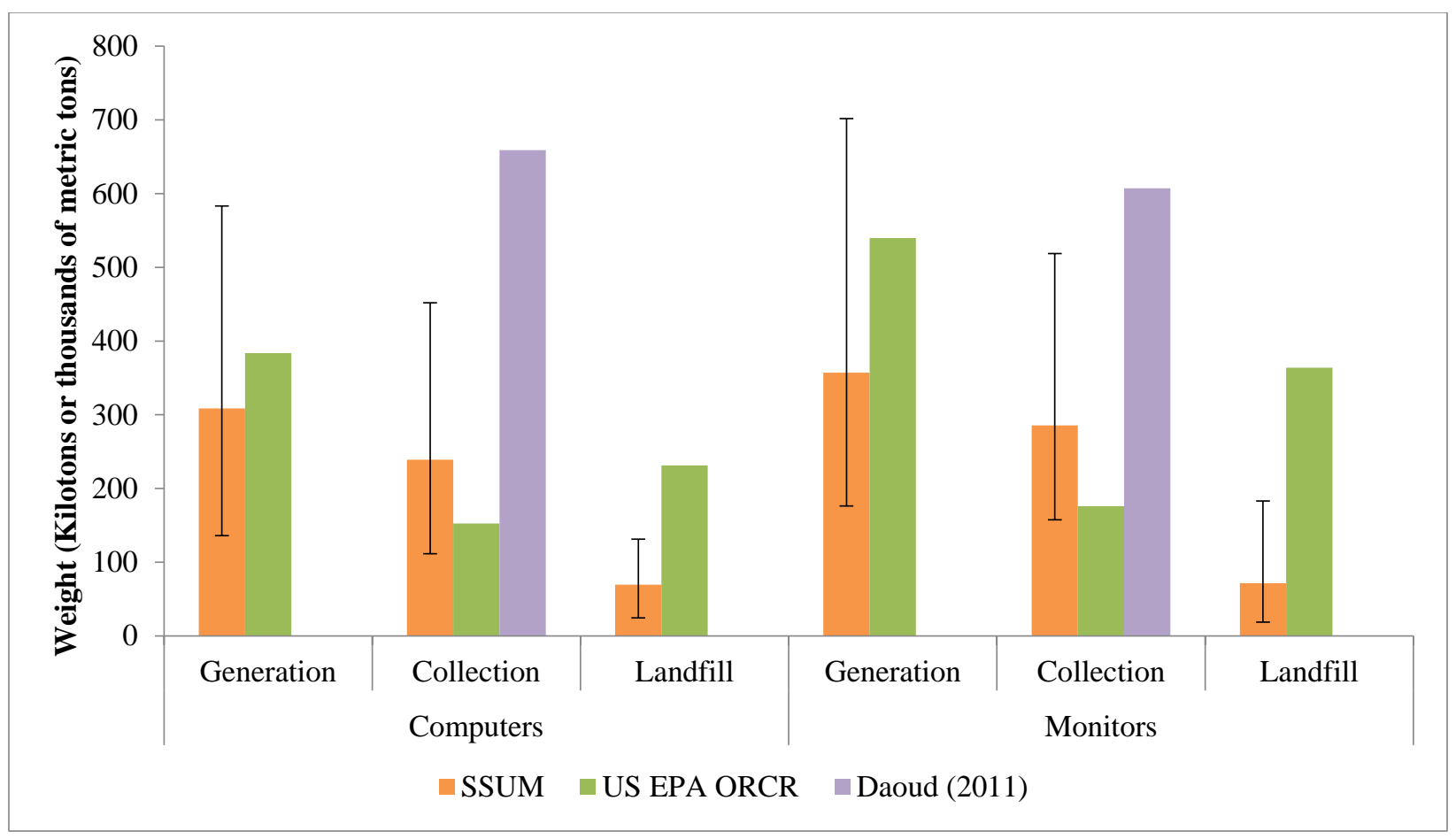

Figure S27: Comparison of SSUM Generation (Gen), Collection (Coll), and Landfill weight in kilotons by product with estimates from US EPA OCRC[2] and Daoud[18]. Columns represent mean and error bars represent $95 \%$ confidence interval.

While the 2010 used computer and monitor generation estimates in the US EPA ORCR study[2] exceed those from the SSUM in this study, the US EPA ORCR study collection estimates are similar to the SSUM collection estimates. Though the sales data used in the SOM and SSUM was very similar to that used in the US EPA ORCR study, the latter assumed lower collection rates, and made different lifespan assumptions, resulting in higher generation estimates but coincidentally similar collection quantities. The collection estimates from Daoud (2011) are greater than the generation and collection estimates from both of the other methods[18]. That suggests that the material flows approaches in the other methods lead to underestimates, or the extrapolation from the recycler survey analyzed in Daoud (2011) resulted in an overestimate. As mentioned in the text, it is likely that the SSUM is an underestimate due to the incorporation of CRT scale factors in the average scale factor. 


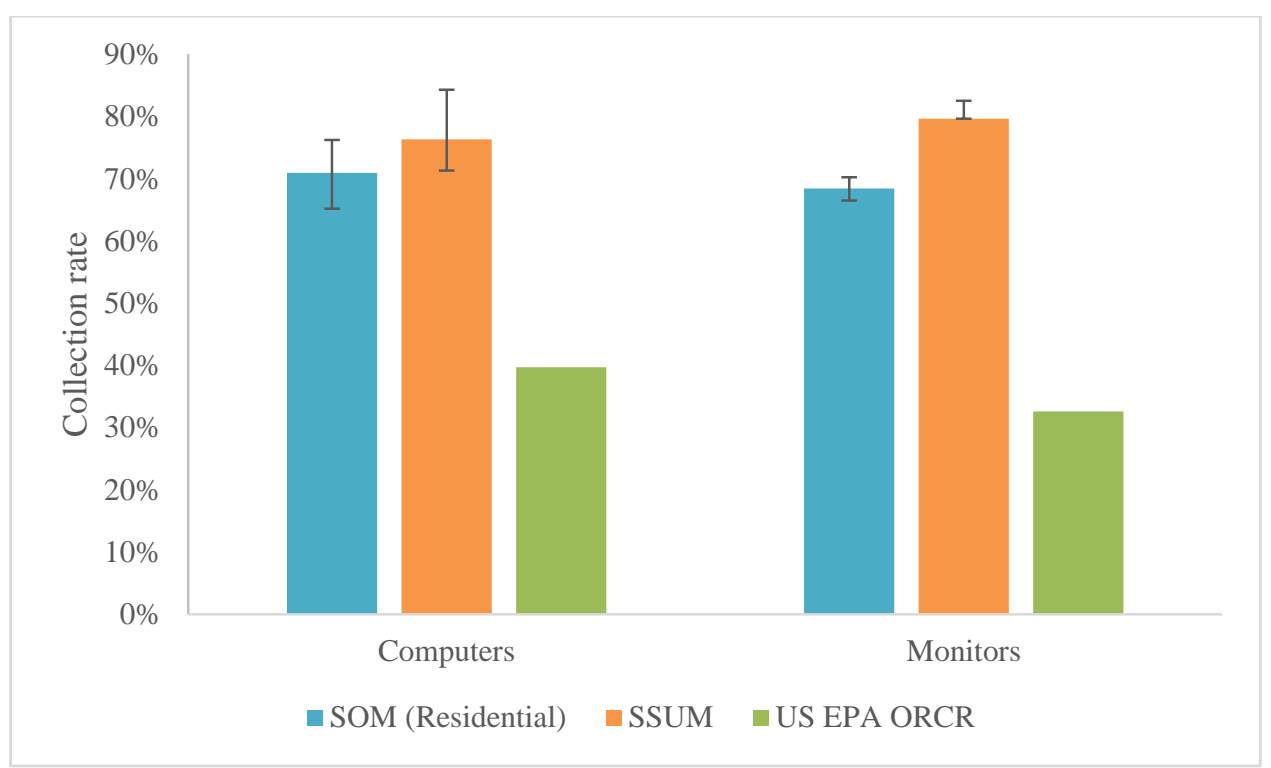

Figure S28: Comparison of 2010 collection rate by product and method with estimates from US EPA ORCR. Columns represent mean values and error bars represent $95 \%$ confidence interval.

Figure S28 demonstrates 'considerable differences in the methods' estimated collection rates. Collection rates could not be calculated for data from Daoud (2011) since it lacked generation estimates. The residential SOM and SSUM collection rates are based solely on surveys of owners, whereas the US EPA ORCR study ${ }^{[19]}$ factored in state program data and electronics recyclers surveys. We assume that the US EPA ORCR study ${ }^{[1919]}$ collection rates are an underestimate since it may not effectively capture all pathways that used electronics arrive at recyclers. 


\section{References}

1. Kahhat R, W. E., Materials flow analysis of e-waste: Domestic flows and exports of used computers from the United States. Resources, Conservation and Recycling 2012, 67, 67 - 74.

2. US EPA ORCR, Electronics Waste Management in the United States Through 2009. In 2011.

3. NCER. NCER Brand Data Management System, sampling share from computer and monitors (weight )- Oregon and Washington Sampling Data. Data:

http://www.electronicsrecycling.org/BDMS/AlphaList.aspx?sort=All

4. Alcorn, W. 2012 CE Recycling and Reuse Survey; Consumer Electronics Association: 2012.

5. Brugge, P. Trends in CE Reuse, Recycle and Removal; Consumer Electronics Association: 2008.

6. E. Williams, R. K., C. Mattick, , Survey of Consumer Purchases and Use of Electronics. In 2009.

7. CR E-waste Survey 2006; Consumer Reports National Research Center (CR): 2006.

8. Census Table 1. Monthly Population Estimates for the United States: April 1, 2010 to November 1, 2012 (NA-EST2011-01-11); 2012.

9. U.S. Census Bureau Population Division, Table 1. Monthly Population Estimates for the United States: April 1, 2000 to December 1, 2010 (NA-EST2009-01)

2009.

10. Census Table 1C. Computer and Internet Use in the United States: 2010. ; 2012.

11. Census, Appendix Table A. Households With a Computer and Internet Use: 1984 to 2009. In 2010.

12. Bureau of Labor Statistics, Technical notes, household data ("A" tables, monthly; "D" tables, quarterly). In 2006.

13. Baldé, C. P., R. Kuehr, K. Blumenthal, S. F. Gill, J. Huisman, M. Kern, P. Micheli, and E. Magpantay E-waste statistics: Guidelines on classifications, reporting and indicators.; United Nations University, IAS-SCYCLE: Bonn, Germany, 2015.

14. Kwak, M.; Behdad, S.; Zhao, Y.; Kim, H.; Thurston, D., E-Waste Stream Analysis and Design Implications. Journal of Mechanical Design 2011, 133, (10).

15. US EIA, Residential Energy Consumption Survey: 2009, 2005, and 2001 Public use microdata files. In 2013.

16. US EPA OSW Management of Electronics Waste in the United States: Approach Two; 2007.

17. US EPA OSW Electronics Waste Management in the United States: Approach I; 2008.

18. Daoud, D. Report Inside the US Electronics Recycling Industry; IDC: 2011.

19. USEPA Electronics Waste Management in the United States Through 2009; U.S. Environmental Protection Agency (USEPA): Washington DC, US, 2011. 